\title{
REVIEW
}

\section{Glucocorticoids and the circadian clock}

\author{
Thomas Dickmeis \\ Institute of Toxicology and Genetics, Forschungszentrum Karlsruhe, Hermann-von-Helmholtz-Platz 1, D-76344 Eggenstein-Leopoldshafen, Germany \\ (Correspondence should be addressed to T Dickmeis; Email: thomas.dickmeis@itg.fzk.de)
}

\begin{abstract}
Glucocorticoids, hormones produced by the adrenal gland cortex, perform numerous functions in body homeostasis and the response of the organism to external stressors. One striking feature of their regulation is a diurnal release pattern, with peak levels linked to the start of the activity phase. This release is under control of the circadian clock, an endogenous biological timekeeper that acts to prepare the organism for daily changes in its environment. Circadian control of glucocorticoid production and secretion involves a central pacemaker in the hypothalamus, the suprachiasmatic
\end{abstract}

nucleus, as well as a circadian clock in the adrenal gland itself. Central circadian regulation is mediated via the hypothalamic-pituitary-adrenal axis and the autonomic nervous system, while the adrenal gland clock appears to control sensitivity of the gland to the adrenocorticopic hormone (ACTH). The rhythmically released glucocorticoids in turn might contribute to synchronisation of the cell-autonomous clocks in the body and interact with them to time physiological dynamics in their target tissues around the day. Journal of Endocrinology (2009) 200, 3-22

\section{Introduction}

\section{The circadian clock}

The physiology of most organisms changes significantly between day and night. This represents a key adaptation to cope with the different environmental challenges the organism faces at different times of day, such as changes in lighting conditions and temperature, food availability or the presence of predators. Many of the rhythmic physiological changes are not simply 'driven' by environmental changes, because the rhythms persist even under constant conditions. Rather, these biological rhythms are generated by an endogenous biological 'clock' or 'pacemaker' which keeps time even in the absence of environmental cues (Dunlap et al. 2004). Characteristically, the period length of this clock is slightly shorter or longer than $24 \mathrm{~h}$ when measured in constant conditions, hence it is termed 'circadian' (=about one day) clock. In order to avoid drifting out of phase with respect to the environment, the circadian clock is reset, or 'entrained', to the local conditions by environmental timing cues such as light or temperature. In the absence of such cues, the clock 'free runs' according to its endogenous period.

\section{A central pacemaker in the brain - the suprachiasmatic nucleus of} the hypothalamus

The simplest concept of a circadian clock is that of an endogenous oscillator, which receives timing information

from the environment through an input pathway and drives physiological rhythms via an output pathway. In mammals, the search for the endogenous oscillator identified a small paired nucleus in the anterior hypothalamus, the suprachiasmatic nucleus ( $\mathrm{SCN}$ ), as the seat of the pacemaker driving rhythms in behaviour and many aspects of physiology, including hormonal secretion (Klein et al. 1991). The SCN receives input from the eyes through the retinohypothalamic tract. The principal light detecting system conveying timing information to the SCN are not the rods and cones, the dedicated visual photoreceptors of the retina, but rather a subset of directly light sensitive retinal ganglion cells that express a special photopigment, melanopsin (Berson 2007, Hankins et al. 2008), and which project directly to the SCN. Here, light input triggers a signalling cascade that changes gene expression and the firing rate of SCN neurons (Antle \& Silver 2005, Maywood et al. 2007). Output projections from the SCN target many different brain regions, among others the subparaventricular zone (sub PVZ), the dorsomedial nucleus $(\mathrm{DMH})$ and the paraventricular nucleus $(\mathrm{PVN})$ of the hypothalamus (Fig. 2; Buijs \& Kalsbeek 2001, Kalsbeek \& Buijs 2002, Saper et al. 2005), and may underlie the circadian changes observed in processes governed by these structures.

\section{The molecular clockwork - a transcriptional negative feedback loop}

Interestingly, single SCN neurons in dispersed culture also show circadian rhythms of electrical activity (Welsh et al. 
1995). This, together with the presence of circadian clocks in unicellular organisms (Roenneberg \& Merrow 2002, Mackey \& Golden 2007), suggested that the oscillator works in a cellautonomous manner. Combined with genetic studies in a variety of organisms, notably in Drosophila and mouse, these findings have led to the elucidation of the basic molecular mechanisms of the circadian clock (Fig. 1; for review see, Ko \& Takahashi 2006; Rosato et al. 2006). The core clock elements turned out to be transcription factors participating in a delayed feedback loop that leads to oscillating gene transcription. In vertebrates, a heterodimer of the bHLH-PAS family members CLOCK and BMAL1 activates transcription of the period (PER) and cryptochrome (CRY) genes upon binding to the so-called E-box regulatory sequences in their promoters. Protein accumulation of PERs and CRYs and their localisation to the nucleus takes several hours and peaks at the end of circadian daytime. The CRY and PER proteins then act to inhibit transcriptional activity of the CLOCK/ BMAL1 heterodimer and thereby shut off their own transcription. This core negative feedback loop is modulated by a number of different mechanisms, which all seem to contribute to the stability and exact timing of the clock cycles. Thus, an accessory feedback loop drives rhythmic expression of the bmal1 gene through retinoic acid-related orphan receptor response element (RORE) regulatory sequences in its promoter. These sequences are sequentially bound by the nuclear receptor proteins RORA, which acts as an activator, and REV-ERB $\alpha$, acting as a repressor (Duez \& Staels 2008). Posttranslational regulation also influences the properties of the feedback loop (Gallego \& Virshup 2007). Several kinases have been shown to phosphorylate clock genes and thereby alter their stability, nuclear localisation or transcriptional activity. Additionally, F-box protein containing ubiquitin ligase complexes have been implicated in feedback loop regulation (Busino et al. 2007, Godinho et al. 2007, Siepka et al. 2007). In the cyanobacterial clock system, which uses genes dissimilar to the vertebrate clock, three clock proteins alone are sufficient to create circadian cycles of phosphorylation in a test tube, suggesting that, at least in this system, a circadian rhythm can be generated without a transcriptiontranslation feedback loop (Nakajima et al. 2005). However, recent results indicate that the phosphorylation rhythm is not strictly required for circadian rhythm generation in the bacterial cells and that the transcription-translation feedback loops appear to be necessary for clock function at low temperatures (Kitayama et al. 2008; for an alternative interpretation of these results see Brunner et al. 2008). Also in Drosophila and in vertebrates, there is evidence that transcriptional regulation plays a crucial role in the clock mechanism and does not serve just as a means of linking clock

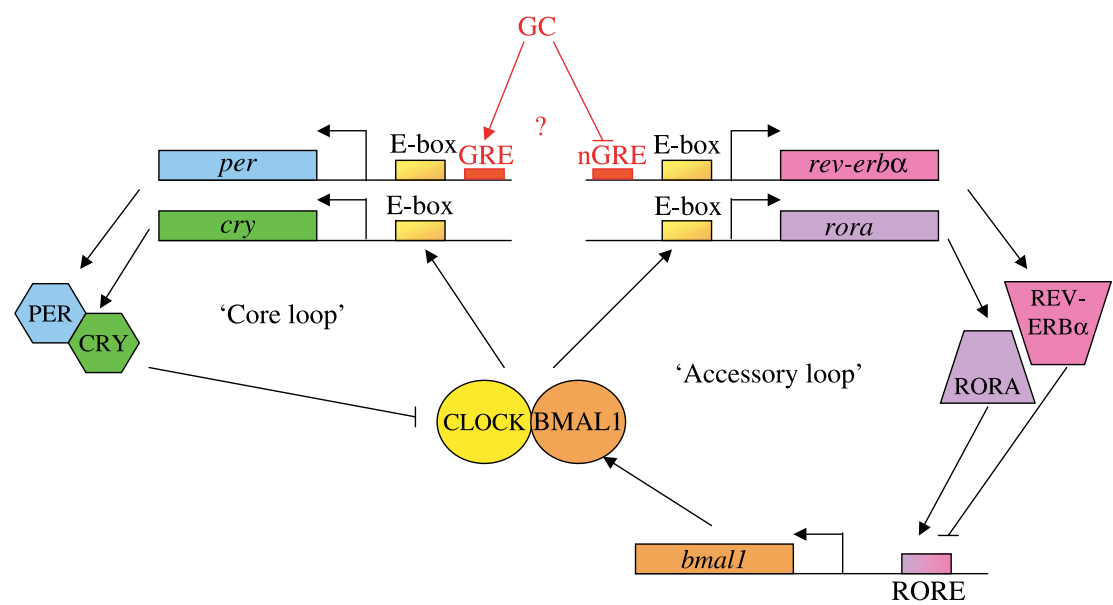

Figure 1 The molecular clock mechanism. 'Core loop': The bHLH transcription factors CLOCK and BMAL1 heterodimerise and bind to E-box enhancer elements. This activates transcription of period and cryptochrome genes, the products of which also heterodimerise and, after translocation to the nucleus, inhibit the activity of the CLOCK/BMAL1 dimer. This shuts down transcription of their own genes. Posttranscriptional and posttranslational modifications (not shown) delay nuclear accumulation of PER and CRY, thereby leading to the approximate $24 \mathrm{~h}$ rhythm of activation and repression on the per and cry promoters. 'Accessory loop': The CLOCK/BMAL1 dimer also binds E-boxes in the promoter of the REV-ERB $\alpha$ and RORA genes. RORA in turn binds a RORE element in the promoter of bmal1 and activates its transcription. REV-ERB $\alpha$ competes with RORA for the RORE binding site and inhibits transcription of bmal1. The resulting cyclical transcription of bmal1 is thought to enhance the core feedback loop. Glucocorticoids (GC) might modulate transcription of certain clock genes by binding to glucocorticoid response elements (GRE) in their promoters. Thus, a positive GRE element appears to mediate per1 induction by glucocorticoids (Yamamoto et al. 2005), whereas the promoter of rev-erb $\alpha$ has been proposed to contain a negative GRE (nGRE) that mediates glucocorticoid induced repression (Torra et al. 2000). 
oscillations to clock output (Sato et al. 2006, Kadener et al. 2008). Thus, despite the increasingly recognised importance of protein modifications in clock regulation, transcriptiontranslation feedback loop mechanisms still appear to be important players in the clock of all systems studied so far (Brunner \& Schafmeier 2006, Zheng \& Sehgal 2008).

\section{'Central' and 'peripheral' pacemakers}

It had long been thought that the circadian clock was the function of a limited number of specialised pacemaker structures such as the SCN or, in lower vertebrates, also the retina and pineal gland (Menaker et al. 1997). These so-called 'central pacemakers' were considered to be responsible for generating all circadian rhythms within the organism. However, some early work also reported the existence of autonomous circadian rhythms in explant cultures of 'peripheral' organs, notably in the adrenal gland (Andrews \& Folk 1964, Andrews 1971) and the heart (Tharp \& Folk 1965). These findings were confirmed after the cloning of clock genes. Basic clock components are not only expressed in the central pacemaker structures, but also throughout the animal, where they also show oscillating expression (Balsalobre 2002). These rhythms persist in organ cultures (Whitmore et al. 1998), as also revealed by real-time imaging of such cultures from bioluminescent transgenic animals carrying clock gene reporter constructs (Yamazaki et al. 2000, Yoo et al. 2004, Kaneko et al. 2006). Even many non-neural cultured cell lines exhibit circadian expression of clock genes (Balsalobre et al. 1998, Whitmore et al. 2000, Nagoshi et al. 2004, Welsh et al. 2004, Carr \& Whitmore 2005). Thus, autonomous peripheral clocks exist in most cells and tissues. These findings have changed the view of the central pacemakers, which are now no longer considered to be the direct drivers of most peripheral rhythms, but instead appear to interact with and coordinate the many autonomous peripheral oscillators.

\section{Circadian regulation of the transcriptome}

Which biological processes are under control of this 'web of pacemakers' (Schibler \& Sassone-Corsi 2002)? Before the advance of microarray gene expression monitoring, few genes that were regulatory targets of clock output pathways had been identified (e.g. dbp, Wuarin et al. 1992; hlf, Falvey et al. 1995; tef, Fonjallaz et al. 1996; pdf, Renn et al. 1999). However, studies in cyanobacteria (Van Gelder et al. 1995, Liu et al. 1995) indicated that a large proportion of the genome might be expressed in a circadian fashion. These estimations have been validated by microarray studies ((Duffield 2003, De Haro \& Panda 2006), see also (Bozek et al. 2007, Keegan et al. 2007) and references therein), showing oscillating transcripts e.g. for $8-10 \%$ of genes in different mouse tissues (Panda et al. 2002, Storch et al. 2002). The number of cycling proteins might be still higher, as a recent liver proteomics study reports circadian changes in up to $20 \%$ of soluble liver proteins, even if their corresponding mRNAs do not cycle (Reddy et al. 2006). Cycling genes fulfil a broad range of functions in all the tissues studied, including peptide synthesis, processing and secretion; vesicle trafficking; detoxification and metabolism (Claridge-Chang et al. 2001, McDonald \& Rosbash 2001, Panda et al. 2002, Storch et al. 2002). The circadian regulation of metabolic pathways observed in these studies often occurs at the level of rate-limiting enzymes (Claridge-Chang et al. 2001, McDonald \& Rosbash 2001, Panda et al. 2002, Reddy et al. 2006).

Interestingly, there is only a little overlap in cycling transcripts between different tissues: even though about $60 \%$ of the genes cycling in one of the tissues are also expressed in the other, they do not cycle there (Panda et al. 2002, Storch et al. 2002). While this certainly reflects tissue-specific circadian regulation, some caution has to be exerted when interpreting the microarray data, since recent meta-analyses show that the overlap of genes identified as cycling between different studies using similar samples is quite limited (Bozek et al. 2007, Keegan et al. 2007). This is most likely due to differences in the mathematical methods for analysis of rhythmicity or to laboratory-dependent differences in microarray protocols and platforms. Nevertheless, the data suggest a model of transcriptional hierarchies with some conserved elements such as E-boxes or ROREs at the top that drive gene expression in certain phases of the circadian cycle (Ueda et al. 2005). These elements could then interact with tissue-specific transcription factor networks to create tissuespecific cycling gene profiles, which all the same influence a largely overlapping set of cellular processes. The exact structure of these transcriptional hierarchies and the links between direct clock targets and downstream processes in different tissues are still largely unknown.

\section{Integration of central and peripheral pacemakers}

How do the central and the peripheral clocks interact in the circadian control of physiology within the animal? Tissuespecific disruption of the liver clock abolishes circadian transcription of most genes in the liver, illustrating the importance of the peripheral pacemaker for circadian regulation of transcription (Kornmann et al. 2007). On the other hand, following ablation of the SCN no circadian rhythm can be detected in the liver transcriptome (Akhtar et al. 2002). Interestingly, organ cultures derived from SCNablated animals still show rhythmic clock gene expression, but with different phases for each cultured organ sample, indicating a loss of synchronisation of peripheral pacemakers within the animal (Yoo et al. 2004). When different samples are pooled for microarray analysis, these desynchronised phases will cancel each other out, and no circadian rhythm is detected. Strikingly, the liver-specific clock arrest also revealed some genes where circadian expression was independent of the peripheral pacemaker and appeared to be directly driven by centrally derived cues (Kornmann et al. 2007). 
The search for mechanisms integrating central and peripheral clock regulation of physiology has brought endocrine rhythms back into focus. Many hormones show circadian patterns of release and are therefore well placed as candidate signals that may coordinate central and peripheral rhythms (Aschoff 1979, Hastings et al. 2007, Haus 2007). Notably glucocorticoids have been implicated in the regulation of peripheral circadian rhythms and are themselves subject to circadian regulation at many levels of organisation.

Here, we review both the circadian regulation of synthesis and release of glucocorticoids as well as their interaction with clock controlled processes. We will first examine SCN control of the hypothalamic-pituitary-adrenal (HPA) axis and then turn towards an alternative route from the SCN to the adrenal gland, namely the autonomic nervous system. We will study the role that the peripheral pacemaker of the adrenal gland itself plays in circadian glucocorticoid secretion and discuss how it might interact with the central control mechanisms. After touching upon potential roles for other peripheral clocks in the nervous system and briefly reviewing circadian regulation of glucocorticoid feedback and stress reactions, we will consider functions of circadian glucocorticoid changes in their target tissues. A role for glucocorticoids in coordinating peripheral pacemakers throughout the body and in the brain will be explored, and we will examine how glucocorticoids interact with peripheral clocks in the control of target tissue dynamics. Finally, we will discuss potential mechanisms by which the cell-autonomous circadian clock might modulate the glucocorticoid signalling pathway, and we will end with an outlook upon some areas for future research.

\section{Circadian patterns of glucocorticoid release}

Glucocorticoid hormones fulfil many different functions in body homeostasis and stress responses (Norris 2007). Their secretion shows pronounced temporal regulation, with both pulsatile ('ultradian' $=$ shorter than a day) and circadian rhythmicity (Chrousos 1998, Haus 2007, Lightman et al. 2008). The circadian peak in glucocorticoid release is locked to the activity phase of the animal: it occurs in the early morning in diurnal and in the early night in nocturnal animals (Cheifetz 1971, Perlow et al. 1981, Lincoln et al. 1982, Klemcke et al. 1989, Van Cauter 1990, Lefcourt et al. 1993, Irvine \& Alexander 1994). Globally, the ultradian pulses occur with a frequency of about 1-2 per hour (Weitzman et al. 1971, Holaday et al. 1977, Tapp et al. 1984, Jasper \& Engeland 1991, Loudon et al. 1994, Sarnyai et al. 1995, Windle et al. 1998a,b), and their amplitude increases towards the end of the day period in nocturnal animals (Chrousos 1998, Windle et al. 1998a,b, Lightman et al. 2008). These rhythms are paralleled by similar rhythms in the adrenocorticotropic hormone (ACTH), albeit less robust and of lower amplitude (Carnes et al. 1988, 1989, Veldhuis et al. 1990, Sarnyai et al. 1995, Gudmundsson \& Carnes 1997, Chrousos 1998). ACTH is released by the corticotrope cells of the pituitary (' $\mathrm{C}$ ' in Fig. 2), binds to melanocortin type 2 receptors in the adrenal cortex (mainly zona glomerulosa and fasciculata; Abdel-Malek 2001) and acts to stimulate corticosteroid synthesis (Fig. 3A; Norris 2007). ACTH release in turn can be stimulated by the secretagogues corticotropin-releasing hormone $(\mathrm{CRH})$, arginine vasopressin (AVP) and oxytocin, which are released into the portal blood stream of the median eminence from nerve terminals projecting from the PVN of the hypothalamus (Fig. 2; Whitnall et al. 1985, Engler et al. 1989, Chrousos 1998, Jacobson 2005). Also CRH synthesis seems to be under circadian control, as its pre-mRNA shows diurnal variations (Watts et al. 2004). However, ACTH release precedes the onset of $C R H$ gene transcription considerably, implicating that coupling of the two processes might be only loose.

Experimental difficulties brought about by the pulsatile nature of release patterns may in part explain the abundance of conflicting reports in the literature regarding the exact parameters of the circadian and ultradian rhythms in the HPA axis. There is also evidence that the mechanistic link between ACTH and glucocorticoid secretion might indeed be less tight than previously thought: under various physiological and pathophysiological conditions, the pulses of ACTH and glucocorticoids do not correlate, indicating dissociation between the two factors (reviewed in Bornstein et al. (2008), see also below). Thus, uncoupling among elements of the HPA axis can be seen at multiple levels.

\section{SCN control of HPA axis activity}

\section{Neuroanatomy of SCN - HPA axis connections}

The circadian aspects of the rhythmic release of glucocorticoids and their tropic hormone ACTH are under control of the SCN, since SCN lesions abolish the rhythms (Moore \& Eichler 1972, Abe et al. 1979, Szafarczyk et al. 1979, Cascio et al. 1987). Interestingly, the SCN also exhibits ultradian rhythms of activity, but at present it is unknown if and how these rhythms might contribute to the ultradian rhythms of the HPA axis and of glucocorticoid release (Yamazaki et al. 1998, Lowry 2002). Since SCN grafts into SCN-lesioned hamsters are able to restore circadian locomotor rhythms, but fail to restore the circadian endocrine rhythms including those of glucocorticoids, axonal connections seem to be required for their circadian control (Meyer-Bernstein et al. 1999). The SCN shows few direct projections to the medioparvocellular division of the PVN (mpPVN; Vrang et al. 1995, Engeland \& Arnhold 2005), where the $\mathrm{CRH}$ and AVP expressing neurons projecting to the median eminence are located (Fig. 2; broken black arrow, Antoni et al. 1983, Swanson et al. 1983, Sawchenko et al. 1984a,b). However, many neighbouring areas in the PVN are also innervated by the SCN ('I' in Fig. 2) and they may contact the hypophysiotropic neurons as well ((Berk \& Finkelstein 1981, Stephan et al. 1981, Watts et al. 1987, Buijs et al. 1993b, Vrang et al. 1995) and references therein). Furthermore, the SCN contacts the subparaventricular zone (subPVZ) and the dorsomedial nucleus of the hypothalamus (DMH), which in turn send 


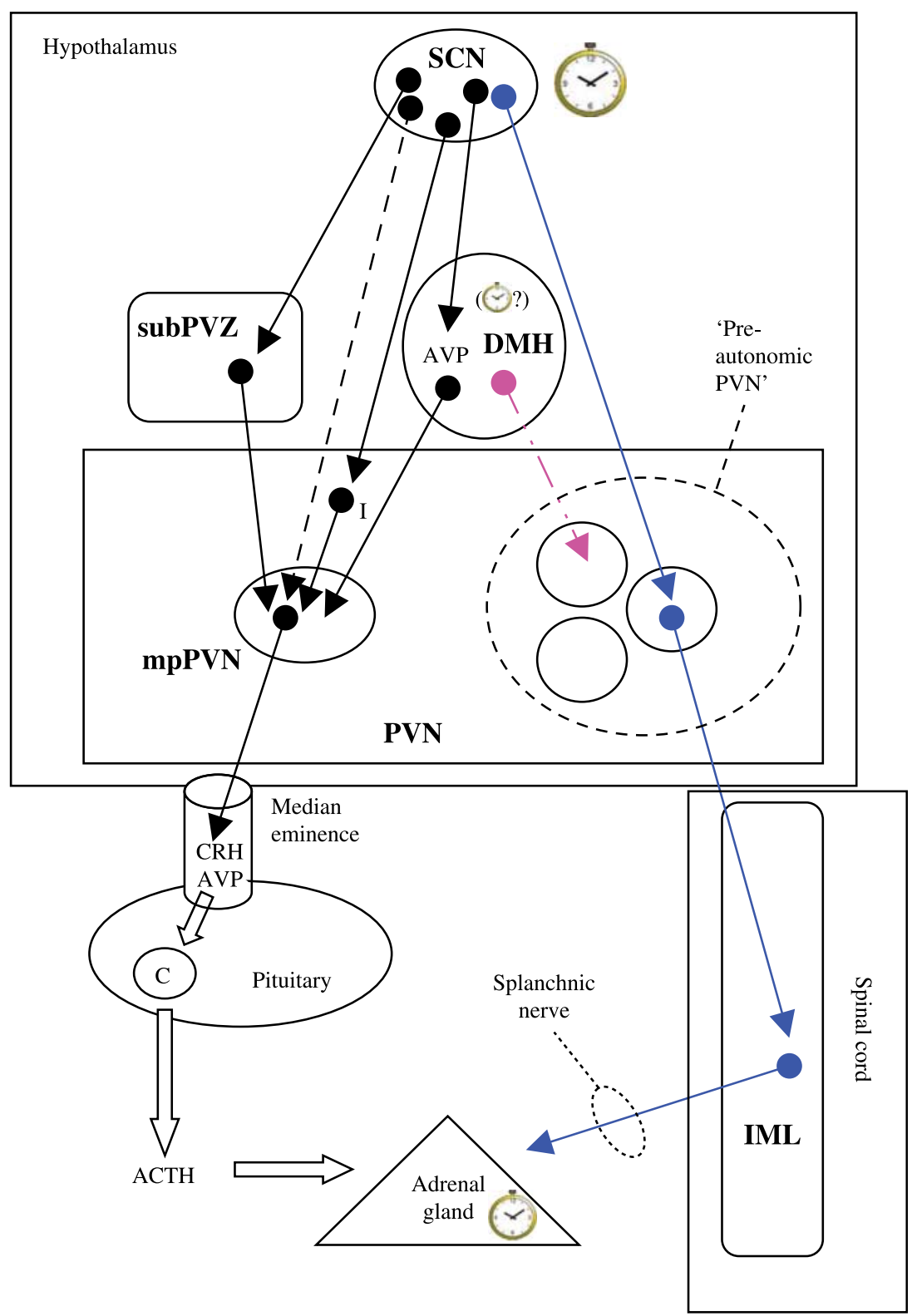

Figure 2 Neural pathways in circadian control of glucocorticoid release. See text for details. Arrows: black arrows: neural projections targeting the HPA axis. Blue arrows: neural projections via the autonomic nervous system. Purple arrow: projection from the DMH to the 'autonomic PVN' distinct from the SCN-adrenal gland pathway. Also the subPVZ projects into this region. Open arrows: humoral transport through the vasculature. Clocks symbolise autonomous pacemakers. Abbreviations: Regions of the nervous system: SCN, suprachiasmatic nucleus; subPVZ, subparaventricular zone; DMH, dorsomedial hypothalamus; PVN, paraventricular nucleus; mpPVN, medioparvocellular division of the PVN; I, interneuron of the PVN; C, corticotrope cell of the pituitary; IML, intermediolateral column of the spinal cord. Hormones and neurotransmitters: AVP, arginine vasopressine; $\mathrm{CRH}$, corticotropinreleasing hormone; $\mathrm{ACTH}$, adrenocorticotropic hormone.

projections to the mpPVN and to many other brain areas (Fig. 2; ter Horst \& Luiten 1986, Buijs et al. 2003, Engeland \& Arnhold 2005). It has been proposed that this pattern of SCN projections to central relay stations allows for an efficient contact with many different brain regions, enabling simultaneous circadian changes in various brain outputs (Watts et al. 1987, Buijs et al. 1993b) and integration with other environmental cues (Saper et al. 2005). Other brain regions targeted by the SCN that may influence 


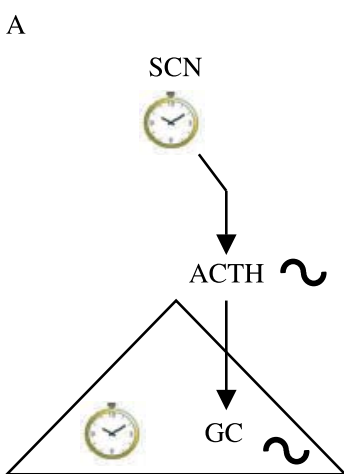

Adrenal gland

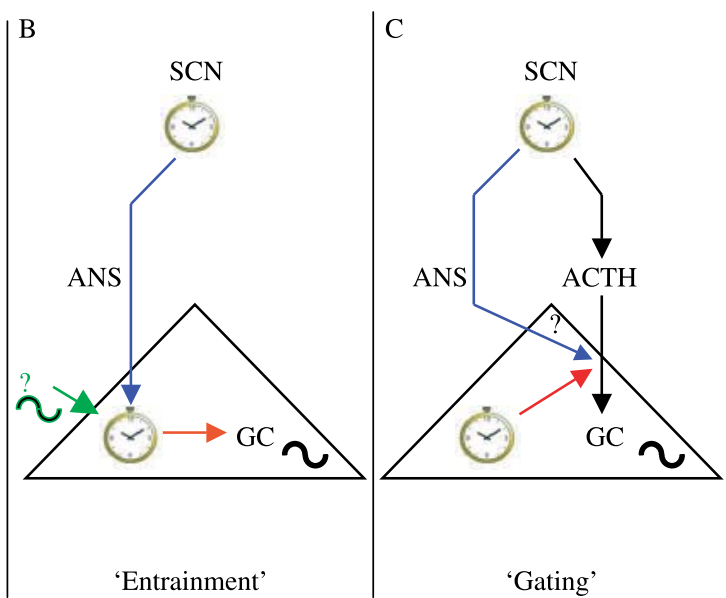

'Entrainment'

'Gating'

Figure 3 Working models for circadian regulation of glucocorticoid secretion. (A) Rhythms in the HPA axis drive circadian ACTH release, which then stimulates glucocorticoid secretion. (B) The autonomic nervous system, perhaps together with other unknown cues, entrains the circadian clock of the adrenal gland. The clock in turn regulates circadian glucocorticoid production and release. (C) The adrenal gland clock, perhaps together with the autonomic nervous system, gates sensitivity of the gland to ACTH in a circadian manner. Abbreviations: ANS, autonomic nervous system; GC, glucocorticoids; SCN, suprachiasmatic nucleus; ACTH, adrenocorticotropic hormone.

PVN output include the arcuate nucleus, the preoptic and supraoptic nuclei of the hypothalamus and the paraventricular nucleus of the thalamus (Saeb-Parsy et al. 2000, Buijs et al. 2003, Pecoraro et al. 2006).

\section{Function of the SCN in HPA axis control}

Morning (trough) corticosterone levels have been reported to increase after ablation of the SCN in rats, indicating that at least part of the circadian control might operate in an inhibitory fashion (Buijs et al. 1993a). One of the main neurotransmitters in the SCN projections towards the PVN/DMH areas is AVP (Buijs et al. 1993b, 1999), and it shows a diurnal release rhythm in the cerebrospinal fluid and the SCN (Reppert et al. 1981, Kalsbeek et al. 1995). Infusion of AVP into the paraventricular/ dorsomedial hypothalamus area inhibits corticosterone release in SCN ablated rats (Kalsbeek et al. 1992), indicating 1) that this peptide alone can mimic the inhibitory effect of the SCN and 2) that the paraventricular/dorsomedial hypothalamic region mediates this SCN effect. In support of this idea, corticosterone release is stimulated when AVP is blocked by antagonist infusion into these brain regions during the circadian peak times of AVP release (Kalsbeek et al. 1992, 1996a,b). Thus, AVP acts twofold in the hypothalamic control of the HPA: a) its release by the mpPVN neurons into the median eminence stimulates ACTH secretion and b) it acts as an inhibitory neurotransmitter in the SCN control of the mpPNVactivity, most likely via the indirect neural pathways detailed above. Interestingly, the inhibitory role of AVP in the nocturnal rat is reversed in the diurnal rodent Arvicanthis ansorgei. Hypothalamic AVP infusion leads to stimulation of corticosterone release, whereas infusion of an antagonist blocks the endogenous corticosterone peaks (Kalsbeek et al. 2008). Thus, whereas the timing of clock gene expression, neural activity and transmitter release by the SCN are similar in both species, the effect on the brain targets is different. The authors propose that the SCN projections might contact different interneurons in the subPVZ and/or DMH areas, inhibitory GABAergic neurons in the case of the rat and excitatory glutamatergic neurons in $A$. ansorgei, which would then exert their effects on PVN neurons. More detailed anatomical and neurochemical studies will be needed to validate this attractive hypothesis.

In addition to the inhibitory SCN control of corticosterone secretion, there is also evidence for a stimulatory role of the SCN in corticosterone release in the rat. Thus, in adrenalectomised animals supplemented with corticosterone pellets (avoiding confounding corticosterone feedback effects and increasing daily ACTH rhythms), the evening rise in ACTH is abolished by SCN ablation (Cascio et al. 1987). Also, the increases in ACTH and corticosterone secretion upon AVP antagonist infusion are most pronounced during the second half of the light period, consistent with the stimulatory activity appearing during this period (Kalsbeek et al. 1996b). The nature of this stimulatory agent is still elusive, although neuromedin $U$ has recently been proposed as a candidate (Graham et al. 2005, Kalsbeek et al. 2006).

\section{An alternative pathway of circadian control: the autonomic nervous system}

\section{Changes in glucocorticoid release are not always dependent on} ACTH changes

In the above discussion, we have focused our attention on the HPA axis and potential SCN actions on circadian glucocorticoid release via this pathway. However, there is evidence that 
the SCN also regulates circadian changes in adrenal activity through alternative routes. In hypophysectomised animals, e.g. gulf killifish (Srivastava \& Meier 1972) or rats (Meier 1976), rhythms of corticosteroid secretion are still present in the absence of cycling ACTH levels. Interestingly, the corticosterone rhythms are lost in the hypophysectomised rats once their adrenal glands are denervated, arguing for the involvement of a neural control mechanism (Ottenweller \& Meier 1982).

\section{A neural SCN-adrenal gland connection}

Significant evidence now points to a neural SCN-adrenal gland connection via the autonomic nervous system (Fig. 2; blue arrows; Buijs et al. 1999, Ueyama et al. 1999; reviewed in Engeland \& Arnhold (2005)). Transneuronal retrograde virus tracing revealed a multisynaptic pathway from the SCN to the adrenal gland, which passes via pre-autonomic PVN neurons as a first relay station to the intermediolateral column (IML) of the spinal cord, the second relay station. The preautonomic PVN neurons contact sympathetic preganglionic neurons in the IML, which then innervate the adrenal gland through the splanchnic nerve (Buijs et al. 1999). Interestingly, this pathway apparently does not overlap with the SCN connections to the PVN via the subPVZ and DMH described above, indicating a separation of the autonomic from the HPA axis targeted pathways of SCN control at the level of the PVN.

The autonomic neural control of circadian glucocorticoid secretion has been demonstrated through two lines of evidence: 1) the neural pathway transmits light information to the adrenal gland that then leads to corticosterone release changes without accompanying changes in the HPA axis and 2) the pathway modulates the adrenal sensitivity to ACTH.

\section{Light influences the adrenal gland via the autonomic SCN pathway}

In rats, light induces a fast (within $5 \mathrm{~min}$ ) repression of corticosterone release when given at the beginning of the night, but not later in the night or at the beginning of the day (Buijs et al. 1999). In a similar study, Ishida et al. (2005) did not report such a decrease in mice, but rather saw an increase after $1 \mathrm{~h}$ during the subjective night only, not during the day; this slower response was not examined by Buijs et al. Importantly, these changes were not accompanied by changes in ACTH, demonstrating that they must be mediated outside the HPA axis. The light input depends on the SCN, since SCN ablation abolished the light dependent glucocorticoid release changes (Buijs et al. 1999, Ishida et al. 2005). The light signal is most likely transmitted through the autonomic SCN-adrenal pathway described above, as light exposure increased adrenal nerve activity, but only if the SCN was intact, and adrenal denervation blocked the light induced corticosterone release changes (Niijima et al. 1992, 1993,
Ishida et al. 2005). The transmission of the signal to the adrenal cortex might involve adrenaline release by the adrenal medulla after the light pulse (Ishida et al. 2005), and such paracrine medulla-cortex interactions have also previously been described upon splanchnic nerve stimulation (Bornstein et al. 1990, Ehrhart-Bornstein et al. 1998). It will be interesting to examine whether these light pulse evoked mechanisms are also involved in the generation of the normal circadian glucocorticoid surge observed at the end of the light phase in nocturnal rodents, a time point not tested in the above studies, and whether similar mechanisms are involved in the glucocorticoid rise at the darkness-light transition in diurnal species.

\section{Neural control of adrenal gland sensitivity to ACTH}

The second evidence for autonomic control over circadian glucocorticoid secretion involves the regulation of the adrenal sensitivity to ACTH (reviewed in Engeland \& Arnhold (2005) and Ulrich-Lai et al. (2006)). This sensitivity is tested by measuring the corticosterone release response to exogenous ACTH when the endogenous ACTH rhythm is blocked by dexamethasone treatment. Dexamethasone is a glucocorticoid receptor (GR) agonist which causes downregulation of ACTH secretion via central glucocorticoid feedback mechanisms (see also below). Under these conditions, ACTH sensitivity shows a diurnal rhythm in rats, with higher sensitivity leading to higher corticosterone release in the evening (Dallman et al. 1978). Ablation of the SCN abolishes these rhythms (Sage et al. 2002) and denervation of the adrenal glands leads to a decrease of corticosterone secretion and of ACTH sensitivity in the evening (Dijkstra et al. 1996, Ulrich-Lai et al. 2006). Together, these findings suggest that neural control mechanisms are involved in ACTH sensitivity regulation and that circadian control might be mediated via the SCN-autonomic-adrenal pathway. Since the ACTH sensitivity studies generally are carried out in the presence of dexamethasone, it will be important to examine potential contributions of direct effects of this drug on sympathetic innervation (Brown \& Fisher 1986) or the adrenal gland itself (Gummow et al. 2006). Indeed, there is some evidence that corticosterone levels can modulate the SCN driven ACTH sensitivity changes (Sage et al. 2002).

One possible mechanism at work in autonomic control of glucocorticoid release from the adrenal gland might be illustrated by recent studies on the role of the autonomic innervation of the liver in daily glucose rhythms (Cailotto et al. 2008). This work revealed that a balance of sympathetic and parasympathetic inputs is required for the glucose rhythm to occur. The rhythm is abolished by either sympathectomy or parasympathectomy, but present when both inputs are removed simultaneously. Future studies will reveal whether similar balance mechanisms could be at work in the regulation of adrenal glucocorticoid secretion. 


\section{The adrenal gland peripheral pacemaker}

\author{
The peripheral clock of the adrenal gland might gate ACTH \\ sensitivity
}

In addition to rhythmic HPA axis activity and neural connections a third player has emerged in the circadian control of glucocorticoid secretion: the peripheral clock of the adrenal gland itself. The existence of such an organautonomous clock was suggested by pioneering work of Andrews and colleagues who showed that adrenal glands exhibit circadian rhythms of metabolic activity and glucocorticoid release even in culture (Andrews \& Folk 1964, Andrews 1971). Later, clock genes were found to be expressed and to cycle also in the adrenal gland (Bittman et al. 2003, Ishida et al. 2005, Lemos et al. 2006, Oster et al. 2006a,b, Torres-Farfan et al. 2006, Fahrenkrug et al. 2008). Experiments by Oster et al. (2006b) suggest that this autonomous adrenal clock contributes to the ACTH sensitivity rhythm: adrenal slice cultures from wild-type mice showed a stronger response to ACTH stimulation in the evening, when the natural peak in glucocorticoid secretion would occur, than around the morning nadir timepoint. This difference was absent in adrenal cultures derived from Per2/Cry 1 double mutant mice, which lack a functional molecular clock. Subsequent in vivo experiments were consistent with these findings. Adrenal gland transplants from wild-type mice into Per $2 / \mathrm{Cr} y 1$ double mutant hosts still secreted corticosterone in a diurnal fashion, even though no ACTH rhythm was present in their clockless hosts. This rhythmic secretion ceased after transfer to constant darkness, which caused a loss of rhythmic clock gene expression in the transplanted adrenals. Thus, a circadian rhythm in adrenal ACTH sensitivity in the transplants would translate the constant ACTH levels in the mutant hosts into different amounts of corticosterone secretion in the morning and the evening. To support this hypothesis, it would be interesting to test whether the differences in response to exogenous $\mathrm{ACTH}$ application observed in the slice cultures are also present in these transplanted adrenals in vivo. One caveat for these experiments stems from the fact that the adrenal glands might become reinnervated upon transplantation in rats (Ulrich-Lai \& Engeland 2000). It would therefore be important to examine whether such ectopic innervation occurs under the surgery protocol used in the mice and if it might give time cues to the adrenal glands independent from the tissueautonomous clock.

\section{Clock regulation of the adrenal transcriptome}

These caveats aside, it appears that the adrenal gland clock gates ACTH input into glucocorticoid synthesis to certain times of day (Fig. 3C). Indeed, among the many genes showing circadian mRNA expression in the adrenal gland, there is the ACTH receptor itself as well as components of its downstream signalling pathway, such as $\operatorname{Adcy} 5$, several G proteins, protein kinase A and protein phosphatase 1 subunits (Oster et al. 2006a,b). It will be instructive to see whether these rhythms are directly driven by the adrenal clock machinery or if systemic cues also contribute to their rhythmic expression. This would require comparison with the transcriptome of a clockless adrenal gland in vivo, similar to the liver studies by Kornmann et al. (2007). Another interesting question is whether the proteins of the ACTH pathway genes, or their posttranslational modifications, equally exhibit circadian rhythms that could then be directly linked to the rhythms in ACTH sensitivity.

Other genes implicated in the biosynthesis of glucocorticoids, such as regulators of cholesterol transport, also show circadian rhythms of expression; interestingly however, the genes previously demonstrated as rate-limiting for synthesis, like steroidogenic acute regulatory protein (STAR) or cytochrome P450 side-chain cleavage enzyme (CYP11a1; Payne \& Hales 2004, Stocco et al. 2005), are not among them (Oster et al. 2006b). This is in contrast to findings in the liver, which showed rate-limiting steps of different physiological pathways as clock targets (Panda et al. 2002 and see above). One could speculate that the rapid regulatory requirements of acute stress response and feedback regulation preclude a tight circadian control of these genes, pushing clock control to other parts of the synthesis pathway.

Circadian expression analysis of the core clock gene mRNAs themselves in the adrenal gland shows differences in expression levels and in cycling between the medulla and different parts of the cortex, reflected also by the somewhat conflicting reports in the literature (Bittman et al. 2003, Ishida et al. 2005, Lemos et al. 2006, Oster et al. 2006a,b, Torres-Farfan et al. 2006, Fahrenkrug et al. 2008). Such expression differences of core clock genes might lead to tissue-specific changes in clock controlled gene expression. Indeed, differential requirements of certain clock genes for clock function in different tissues and for different target genes are currently being discussed (Oishi et al. 2000, Reick et al. 2001, Debruyne et al. 2006, 2007a,b, Kennaway et al. 2006, Bertolucci et al. 2008).

\section{Does the autonomic nervous system regulate the adrenal clock?}

The adrenal clock might be the link that integrates the findings on neural control of corticosterone secretion into a common framework. Nocturnal light exposure signalled via the splanchnic nerve elevated per1 gene expression in the adrenal (Ishida et al. 2005), indicating that environmental light information might act to reset the peripheral clock via this pathway. Changes in clock gene expression might then be passed on to gene expression in the ACTH pathway and thereby change adrenal gland receptiveness for the hormone (Fig. 3B and C). At present, it is not known if and how the light induced per1 expression leads to sustained changes in clock rhythms. A role for the autonomic nervous system in peripheral clock regulation is supported by findings that chemical denervation of sympathetic liver input led to 
flattened rhythms of clock gene expression (Terazono et al. 2003, but see also Cailotto et al. 2005 for different results), and sympathetic innervation has also been shown to modulate clock gene expression in submaxillary salivary glands in rats (Vujovic et al. 2008). Thus, denervation of the adrenal gland might lead to desynchronisation of clock gene expression, and thereby influence ACTH sensitivity rhythms. An examination of clock gene expression in denervated adrenals is required to explore this possible mechanism.

Alternatively, signals from the autonomic nervous system might have more direct (and maybe faster) effects on corticosterone synthesis or ACTH sensitivity in the adrenal gland. To functionally dissect adrenal clock dependent and independent mechanisms in circadian glucocorticoid secretion, tissue-specific arrest of the peripheral clock in the adrenal gland will be necessary, e.g. using the methods recently applied to the liver clock (inducible overexpression of $R E V-E R B \alpha$ to block the feedback loop, Kornmann et al. 2007) or the retina clock (tissue-specific deletion of the bmal1 gene, Storch et al. 2007). Gene expression patterns from such clockless adrenals could then be compared with those of wild-type glands, throughout the circadian cycle or after a nocturnal light pulse. This will reveal adrenal clock independent mechanisms of circadian glucocorticoid control (Fig. 3A and C). Such systemic mechanisms doubtlessly exist, as adrenal glands from the clockless $C r y 1 / \operatorname{Per} 2$ mutants transplanted into wild-type hosts still secrete corticosterone rhythmically, albeit only with 40$50 \%$ of the amplitude seen in wild-type control grafts (Oster et al. 2006b). The full extent of these control mechanisms in vivo will only be revealed in normally innervated adrenals lacking a circadian clock.

Since adrenal medulla-cortex interactions have been proposed to play a role in glucocorticoid rhythms (see above), one could try to generate medulla and cortex-specific clock arrest animals and examine tissue-specific clock contributions to the rhythms. In this context, it would also be interesting to look at a potential role for the clock in the intra-adrenal CRH/ACTH feedback system (Ehrhart-Bornstein et al. 1998).

\section{Do nervous system clocks outside the SCN contribute to glucocorticoid rhythms?}

\section{Peripheral clocks in the nervous system}

The proposed interaction of the adrenal peripheral clock with systemic cues raises the interesting possibility that clocks in the pathway downstream of or parallel to the SCN might also contribute to circadian glucocorticoid secretion. Indeed, circadian rhythms of clock gene expression have been described in explants of the PVN (Abe et al. 2002) and of the pituitary (Yoo et al. 2004), but very little is known about the functions of these autonomous circadian rhythms. As in the case of the adrenal gland, tissue-specific arrest of the clock will clarify if and how glucocorticoid rhythms depend on these clocks.

\section{The 'food-entrainable oscillator' clock}

One such potential additional clock that might influence the circadian rhythm of glucocorticoid secretion is the postulated 'food-entrainable oscillator' (FEO). The daily rest/activity cycle of the animal also generates a feeding/fasting cycle, with most of the food ingested during the night in rodents. When food becomes restricted to certain times of the day, the animals display an increase in activity prior to the feeding time, which continues also in the absence of food on consecutive days and is therefore generated endogenously. The presence of an independent FEO was suggested based on the observation that on such a time restricted feeding scheme, the rhythms of food anticipatory behaviour and physiology, including corticosterone secretion (Krieger et al. 1977), occur even in SCN-lesioned animals (reviewed in Hiroshige et al. (1991), Mistlberger (1994), Stephan (2002), Pecoraro et al. (2006) and Mendoza (2007)). Some studies claim that the $\mathrm{DMH}$, which we have already encountered as a major relay station for SCN input into the PVN (Fig. 2), may be the site of the FEO (Gooley et al. 2006, Mieda et al. 2006, Fuller et al. 2008), but this is questioned by others ((Landry et al. 2006, 2007), see also (Davidson 2006, Herzog \& Muglia 2006, Gooley \& Saper 2007, Landry \& Mistlberger 2007)).

While food anticipatory activity rhythms remain in some clock mutants (Dudley et al. 2003, Pitts et al. 2003, Iijima et al. 2005), the clock genes bmal1 and per 2 have been proposed to be crucial for the food-entrained oscillator (Feillet et al. 2006, Fuller et al. 2008). Fuller et al. (2008) injected adenoassociated viral vectors carrying the bmal 1 gene under control of its own promoter into the DMH of arrhythmic bmal1 knockout mice. In this way, they were able to restore foodentrained rhythms in the mutant mice, indicating that clock function in this structure alone is sufficient for food entrainment. It will be interesting to see whether also corticosterone secretion patterns are restored by this procedure, or whether they would additionally require a rescue of the adrenal clock.

\section{Circadian rhythms of feedback sensitivity and stress responsiveness}

Glucocorticoids themselves contribute to shaping the circadian rhythm via negative feedback regulation of ACTH release (Jacobson 2005). This feedback is mediated by mineralocorticoid receptors (MR) and GR in brain and pituitary. Despite its name, the MR binds glucocorticoids with higher affinity than the GR. The GR appears to exert predominant effects in the pituitary, while MR mediates the brain effects. Since MR expression in the brain is highest in the hippocampus and septum (Arriza et al. 1988), the brain mediated feedback seems to stem mainly from extrahypothalamic sites. The sensitivity of ACTH release to glucocorticoid feedback is highest during the trough point of the circadian glucocorticoid rhythm and appears to depend 
on only MR at this time. Feedback sensitivity is lowest at the peak point and involves binding of glucocorticoids to both MR and GR (Dallman et al. 1993, Jacobson 2005). Recently, it has been proposed that also a membrane bound MR might play a role in feedback regulation by mediating more rapid responses than the classical 'genomic' (=nuclear receptorlike) action of MRs (Joels et al. 2008).

Also the responsiveness of the HPA axis to stress has been shown to vary diurnally (e.g. Sage et al. 2001, Kalsbeek et al. 2003, Atkinson et al. 2006 and references therein). The precise nature of the stress seems to be important in these responses: It has been suggested that, at least in rats, psychological stresses (such as a novel environment or restraint) elicit the largest response early during the day, in the rest phase. By contrast, physical stresses (such as hypoglycaemic shock) do so later in the day, at the onset of activity. Physical stress information appears to be relayed to the PVN mainly via the brainstem, whereas the psychological stresses require interpretation from higher brain centres and involve the limbic system (Jacobson 2005). The SCN might differentially interfere with signals from these different brain structures to the PVN, e.g. inhibit input from physical stressors later in the day while enhancing input from psychological stressors at the same time point. More detailed neuroanatomical and functional studies are required to test this hypothesis. Stress also appears to feedback on the clock control of the glucocorticoid rhythms. Chronic stress can flatten the circadian rhythm of glucocorticoid production and increase the frequency of the ultradian pulses (Windle et al. 2001, Lightman 2008), thereby suggesting an involvement of the clock in stress related diseases. Insight into which of the various modes of circadian control over corticosteroid secretion discussed above (Fig. 3) are involved in the response to different stressors might pinpoint suitable entry points for therapeutic intervention in stress connected disorders.

\section{Are different systemic pathways used for circadian versus stress control of glucocorticoid secretion?}

In summary, it appears that clock control of glucocorticoid secretion does not primarily operate through the HPA axis, but more via the adrenal clock itself and sympathetic input to the adrenal. In the circadian system, cycling of ACTH levels might just form an additional layer of security contributing to the circadian gating of corticosterone secretion by the adrenal gland. By contrast, ACTH-dependent glucocorticoid regulation might play a more prominent role in acute stress responses (Kalsbeek et al. 1996b, 2003). As mentioned earlier, dissociation of ACTH and glucocorticoid responses has been observed in many other physiological and especially clinical situations and receives increasing attention (Bornstein et al. 2008). Hence, although ACTH is required for baseline glucocorticoid production, its role in glucocorticoid regulation seems to be more complex than previously thought.

\section{Glucocorticoids and the regulation of peripheral clocks}

Glucocorticoids are not just a circadian output of the adrenal gland, downstream of central and peripheral clocks; they can also influence the circadian clock itself and interact with other clock outputs in the circadian regulation of physiology (Fig. 4).

Thus, glucocorticoids have been implicated in the synchronisation of circadian gene expression by serum shock in cultured fibroblasts (Balsalobre et al. 1998). Transient treatment of rat-1 fibroblasts with the GR agonist dexamethasone alone leads to circadian rhythms of clock gene expression similar to those seen after a serum shock (Balsalobre et al. 2000). Dexamethasone injections were also able to phase shift clock gene expression in the liver in vivo. These phase shifts were not present in the livers of mice carrying a liver-specific GR gene disruption, indicating that this receptor mediates the phase shifts. Interestingly, however, clock gene expression in the GR-less livers was identical to wild-type livers, arguing that glucocorticoids are not strictly required for the synchronisation of this peripheral oscillator. In another experimental setup, restraint stress was used as a more physiological means to raise glucocorticoid levels. Under these conditions, per1 was reported to be acutely induced in mouse peripheral tissues, most likely through a functional glucocorticoid response element (GRE) in its promoter (Fig. 1). However, it is the only core clock gene for which a response was observed, therefore overall clock function seems not to be perturbed via this induction (Yamamoto et al. 2005). Finally, transcription of the clock accessory loop element REV-ERB $\alpha$ has been shown to be repressed by glucocorticoids (Fig. 1; Torra et al. 2000), but the precise mechanism of this control and its function in clock regulation remain unexplored. It is possible that glucocorticoid repression of rev-erb $\alpha$ transcription might be more associated with the additional roles of this gene in metabolism regulation (Duez \& Staels 2008).

\section{Glucocorticoids modulate food entrainment of peripheral clocks}

Taken together, the effect of glucocorticoid administration on peripheral clock entrainment is not well understood. Nevertheless, a contribution of glucocorticoids to liver oscillator entrainment is revealed under conditions of daytime restricted feeding. Limiting food availability to the day, the period of rest in nocturnal rodents, leads to a decoupling of peripheral clocks from the central pacemaker. Clock gene expression in the SCN remains linked with the light phase, while the phase of peripheral pacemakers adapts to the feeding regime, leading to phase shifts of up to $12 \mathrm{~h}$ (Damiola et al. 2000, Hara et al. 2001, Stokkan et al. 2001). As mentioned above, corticosterone secretion also adapts to the new feeding schedule by showing a food anticipatory peak. Interestingly, injections of corticosterone into rats at the time when this food anticipatory peak would occur did not induce the phase 
A

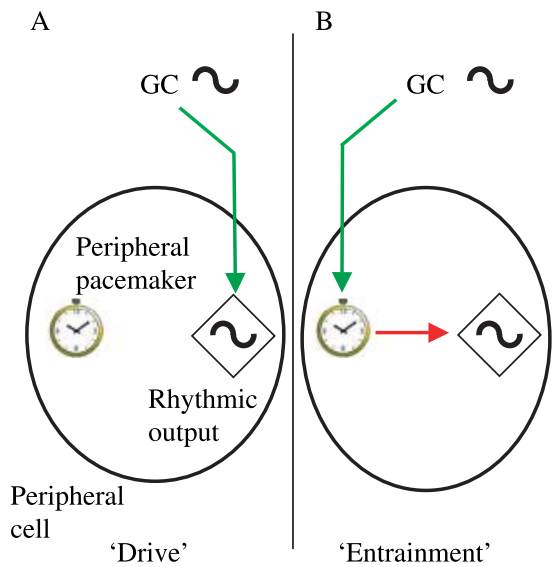

$\mathrm{C}$

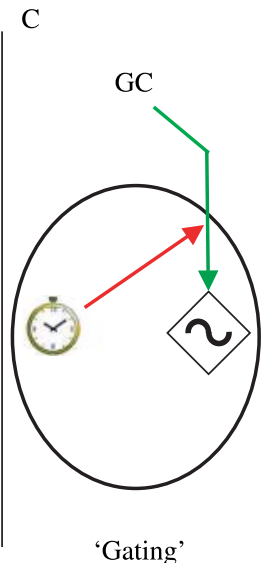

$\mathrm{D}$

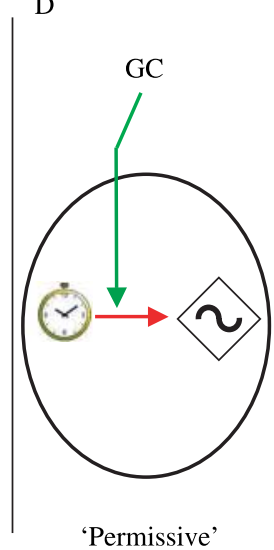

Figure 4 Working models for circadian regulation by glucocorticoids. (A) Rhythms in glucocorticoid concentrations drive circadian output rhythms in the target tissue. (B) Glucocorticoid changes entrain peripheral circadian clocks, which in turn control circadian rhythms in the tissue. (C) Peripheral clocks gate the glucocorticoid input to physiological processes in a circadian manner. (D) Glucocorticoids are required as permissive agents for circadian clock control to operate in rhythmic tissue processes. GC, glucocorticoids.

shifts caused by restricted feeding (Stokkan et al. 2001). Therefore, the changes in endogenous glucocorticoid secretion observed under restricted feeding appear not to be the reason for the food induced phase shifts. However, glucocorticoids may play a modulatory role in food entrainment. In adrenalectomised mice and mice with a liver-specific GR mutation, the phase shifts towards daytime feeding occur more rapidly, whereas phase shifts back to nocturnal feeding are unaffected (Le Minh et al. 2001). Thus, it appears that glucocorticoids can inhibit an as yet unknown signalling pathway that promotes adaptation to non-naturalfeeding times. This modulation might be particularly strong when the potent GR agonist dexamethasone is injected, leading to phase shifts even when the other hypothetical pathway shows unaltered activity.

Glucocorticoids are required for cycling expression of clock genes in some brain regions

Some peripheral clock genes in brain regions outside the SCN might require glucocorticoids for their circadian expression. per2 expression in the oval nucleus of the bed nucleus of the stria terminalis (BNSTov) and in the central nucleus of the amygdala is severely blunted in adrenalectomised animals (Amir et al. 2004, Lamont et al. 2005). Interestingly, these rhythms can be restored through corticosterone replacement via the drinking water, which leads to a diurnal rhythm of plasma corticosterone in the animals, but not via implantation of constant-release pellets that result in constant peak levels of corticosterone (Segall et al. 2006). Thus, although per2 expression at least in the BNSTov is also affected via neural projections from the SCN (Amir et al. 2004), circadian corticosterone changes seem to directly contribute to the rhythms, with constant levels not sufficient for rescuing circadian expression. In one model, the changing glucocorticoid levels might directly drive per 2 expression changes (Fig. 4A). Glucocorticoids might also interact with other hormones shown to regulate circadian per 2 expression in the brain (Amir \& Robinson 2006, Perrin et al. 2006), or affect its expression via targeting the peripheral clock machinery itself (Fig. 4B). To decide between these possibilities, it will be important to examine whether glucocorticoids also affect expression of other clock genes and core clock function in these brain structures, and whether a functional peripheral clock is required for the glucocorticoid regulation of per2 expression. Interestingly, purely systemic regulation of circadian per2 expression was observed in animals with clockless livers (Kornmann et al. 2007; see also Reddy \& Maywood 2007), indicating that a drive mechanism may contribute to clock gene regulation. Redundancy of systemic and peripheral control of clock gene expression might enhance the robustness of the circadian system.

Glucocorticoid-dependent circadian gene expression in certain brain regions might also be involved in feedback of glucocorticoids to the SCN (Buijs \& Escobar 2007): the circadian transcription of tryptophan hydroxylase-2, the ratelimiting enzyme of serotonin synthesis, in the raphe nucleus is abolished in adrenalectomised rats supplemented with basal (=diurnal) corticosterone levels, but can be reinstated by corticosterone replacement in the drinking water (Malek et al. 2007). Serotonergic projections from the raphe nucleus to the SCN, which have been suggested to affect light entrainment of the clock (Meyer-Bernstein \& Morin 1999, Morin 1999, Sage et al. 2004), might thus be a site of glucocorticoid feedback to the central clock. In addition, many other brain regions involved in the control of adrenal glucocorticoid 
release receive serotonergic input from the raphe nucleus (reviewed in Lowry (2002)) and might be influenced by glucocorticoid dependent circadian serotonin synthesis.

\section{Glucocorticoid interactions with transcriptional clock outputs in peripheral tissues}

Part of the circadian liver transcriptome is dependent on the adrenal gland

Besides their actions on peripheral clock gene expression, other mechanisms might link glucocorticoids to circadian gene expression changes in peripheral tissues. Oishi et al. (2005) examined circadian gene expression changes in the liver of adrenalectomised mice compared with sham-operated controls. For 100 out of the 169 cycling genes identified in this study circadian expression was dependent on the adrenal gland. Expression of several clock genes was not affected by adrenalectomy, in line with the findings in liver-specific GR knockout mice (Balsalobre et al. 2000). To more clearly define the glucocorticoid contribution to liver transcriptome regulation, as opposed to that of other adrenal gland derived cues, it would be informative to compare the transcriptomes from adrenalectomised animals with those from liver GR-deficient animals. Some of the adrenal gland dependent genes (e.g. the biosynthetic pathway genes HMG CoAreductase, ornithine decarboxylase and lipin 1) were shown to be induced transiently upon bolus dexamethasone injections, but this did not reinstate circadian transcription with the appropriate phase within the $24 \mathrm{~h}$ examined. Therefore, the authors suggest that circadian glucocorticoid rhythms might drive circadian expression of these genes without involvement of the peripheral clock (Fig. 4A), but a more thorough test of this hypothesis would require analysis for longer than $24 \mathrm{~h}$ and in a clockless liver (Kornmann et al. 2007).

Also indirect effects on other hormonal pathways might play a role. Insulin levels are low in adrenalectomised mice (Dallman et al. 1993), suggesting that lack of this hormone might cause some of the effects of adrenalectomy. This is supported by the finding that circadian glucokinase expression in the liver, which is dependent on the adrenal gland, is also abolished when insulin levels are decreased by streptozotocin-mediated pancreatic $\beta$-cell destruction (Oishi et al. 2005). By contrast, HMG-CoA reductase was not affected by insulin reduction and therefore appears to be more directly dependent on the glucocorticoids. The importance of such indirect hormonal crosstalk mechanisms in liver transcriptome regulation under more physiological conditions remains to be established.

\section{Glucocorticoids might help to synchronise circadian liver gene transcription via HNF4A}

As mentioned above, circadian transcription in the liver is desynchronised after SCN lesion. Reddy et al. (2007) have recently reported that a single dexamethasone treatment of
SCN-lesioned mice is sufficient to synchronise about $60 \%$ of the circadian liver transcriptome (as followed through three timepoints over $36 \mathrm{~h}$ ). Also in muscle tissue, roughly $50 \%$ of the circadianly regulated genes have been reported as glucocorticoid responsive genes (Almon et al. 2008). A caveat for these studies is that the glucocorticoid regulation seen with these treatments may just reflect a glucocorticoid response to homeostasis threats, as in stress, which acts independently of or even overrides the circadian regulation. To clarify this issue, a comparison with stress induced transcriptome changes in these organs would be insightful (similar to e.g. Reyes et al. 2003, Kassahn et al. 2007).

Analysis of a subset of the synchronised genes from the liver study showed that two-thirds of the examined promoters contain GRE elements, often combined with E-boxes. Another enriched element was binding sites for HNF4A, which itself is a glucocorticoid-sensitive circadian gene. Overall, these findings suggest that glucocorticoids may influence circadian transcription in the liver at multiple levels: through direct effects via GREs, via indirect effects through other target genes such as $h n f 4 a$, via effects on clock gene expression itself and by combinations of any of these mechanisms on different promoters. As for the adrenalectomy studies, further dissection of the relative contributions of these mechanisms will require more detailed analysis of the transcriptomes of clockless and GR-less livers.

\section{Glucocorticoids and circadian cell cycle rhythms}

One important process under circadian regulation is the cell cycle. Rhythms of cell proliferation are evident from cyanobacteria to humans (Bjarnason \& Jordan 2000, Mori \& Johnson 2000), and several cell cycle genes have been shown to be under transcriptional control by circadian clock factors (Reddy et al. 2005, Hunt \& Sassone-Corsi 2007, Vallone et al. 2007). Our recent study in zebrafish larvae has indicated a role for glucocorticoids in the regulation of these rhythms (Dickmeis et al. 2007). Circadian cell cycle rhythms are present both in the larvae and in zebrafish-derived cell lines, implying a cell-autonomous clock regulation also in this species (Dekens et al. 2003). However, the examination of pituitary mutant larvae revealed that, in vivo, the rhythms depend on systemic input from this gland (Dickmeis et al. 2007). Analysis of mutants with overlapping pituitary cell type deficiencies pinpointed the corticotrope lineage as the source for the required signal. Mutants possessing only reduced numbers of the corticotrope cells contained lower cortisol levels than wild-type larvae. Importantly, cell cycle rhythms in these mutants could be rescued by tonic treatment with dexamethasone. Thus, glucocorticoids might act as permissive signals that enable peripheral clock control of the cell cycle (Fig. 4D); alternatively, the peripheral clocks might gate glucocorticoid input into the cell cycle machinery (Fig. 4C). The circadian changes of glucocorticoid levels themselves are not required for their action on the circadian cell cycle 
rhythms, but might constitute an additional level of security to ensure proper signalling input to the cell cycle machinery (and their cycling levels might also be of essential importance for other processes, see above). It will be interesting to see whether similar mechanisms also operate in the mammalian system, e.g. in the circadian rhythms observed in liver regeneration after partial hepatectomy (Matsuo et al. 2003), where liver-specific disruption of the GR would allow direct testing of the glucocorticoid contribution.

\section{Circadian modulation of GR signalling in the target tissues}

The GR pathway is the main signalling pathway activated by glucocorticoids, and it is modulated by and interacts with a wealth of other signalling pathways (Grad \& Picard 2007, Kassel \& Herrlich 2007, Stahn et al. 2007). Modulation can occur at various levels (Fig. 5): pre-receptor control of glucocorticoid availability by glucocorticoid metabolising enzymes, association with heat shock proteins (HSPs), phosphorylation of the receptor and interaction with transcriptional cofactors and other transcription factors in the nucleus. In several of these processes, circadian rhythms are observed, and they might cooperate with the circadian glucocorticoid signal in the generation of circadian outputs.

\section{Local glucocorticoid metabolism}

Local metabolism regulates access of the circulating glucocorticoids to their receptors (Chapman \& Seckl 2008). Hydroxysteroid 11-beta dehydrogenase (HSD11B) enzymes catalyse conversion between active 11-hydroxy-glucocorticoids and their inactive 11-keto forms. The type 2 enzyme shows high expression in mineralocorticoid target tissues, where it inactivates glucocorticoids and thereby allows mineralocorticoids to bind the MR despite this receptor's high affinity for glucocorticoids. The type 1 enzyme exhibits a more widespread expression and primarily catalyses the opposite reaction, thereby regenerating and 'amplifying' glucocorticoid concentrations in the cell (Fig. 5I). Rat Hsd11b1 mRNA expression shows a diurnal rhythm in the hippocampus, but not in peripheral tissues (Buren et al. 2007). Circadian rhythms of glucocorticoids are flattened in Hsd11b1 knockout mice, mainly owing to an increase in diurnal levels. This has been suggested to reflect attenuated glucocorticoid feedback, as also stress induced increase in corticosterone is not properly inhibited by exogenous glucocorticoids (Harris et al. 2001). Surprisingly, however, liver-restricted rescue of $H s d 11 b 1$ expression in Hsd11b1 knockout mice is sufficient to rescue HPA axis dysfunction, including the circadian aspects of it (Paterson et al. 2007). Thus, hepatic metabolism of glucocorticoids seems to be of crucial importance for the overall glucocorticoid regulation. Therefore, the in vivo relevance of circadian Hsd11b1 expression in the brain remains to be determined.
Circadian regulation of the $G R$

Before binding of its glucocorticoid ligand and subsequent nuclear translocation, the GR resides in the cytoplasm as a dynamic complex with several HSPs and HSP associated proteins (Fig. 5II; Grad \& Picard 2007). Many HSPs show circadian regulation, and they have been suggested to convey systemic circadian temperature changes to peripheral tissues and thereby contribute to clock entrainment in the periphery (Brown et al. 2002, Kornmann et al. 2007, Reinke et al. 2008). Hence, circadian regulation of HSP/GR complexes, as recently reported for the hippocampus (Furay et al. 2006), might contribute to GR dependent circadian clock outputs. Also expression of the GR mRNA itself can be under circadian regulation (Fig. 5III). A global survey of circadian nuclear receptor mRNA expression in mouse metabolic tissues found circadian GR expression in white and brown adipose tissue (interestingly, with different peak phases), but not in muscle or liver (Yang et al. 2006). Also in the brain, circadian rhythms of GR mRNA have been reported (Herman et al. 1993). Additionally, transcriptional cofactors of nuclear receptors might modulate GR signalling (Fig. 5IV). Thus, the cofactor PGC1 $\alpha$ has recently been implicated in circadian clock function (Liu et al. 2007) and can also interact with the GR (Knutti et al. 2000, Yoon et al. 2001). Finally, as mentioned above for HNF4A, GRs might interact with clock regulated transcription factors at the promoter level, including the core clock factors themselves (Fig. 5V). These mechanisms of differential circadian regulation at the glucocorticoid target cell level could cause differential circadian receptiveness of different tissues and thereby gate glucocorticoid responses to certain times of day (Fig. 4C).

The emerging picture is that a dynamic glucocorticoid signalling machinery receives an equally dynamic glucocorticoid signal which then interacts with various dynamically regulated cofactors and signalling pathways to shape target tissue-specific responses. A precise understanding of these processes will require combinations of in vivo imaging of the network components with systems biology approaches in order to generate predictive models of temporal regulation of tissue physiology.

\section{Some areas for future research}

As evident from the data presented above, much is still to be learned about the precise molecular mechanism by which glucocorticoids and the circadian clock interact to time target tissue dynamics. This includes the functions of the ultradian rhythms in glucocorticoid release and their relation to the circadian clock. There is evidence that the clock also contributes to ultradian pulsatility (Loudon et al. 1994), but the mechanisms through which this is achieved are unknown. Furthermore, more information is needed on how circadian dynamics in the target tissue integrate with 


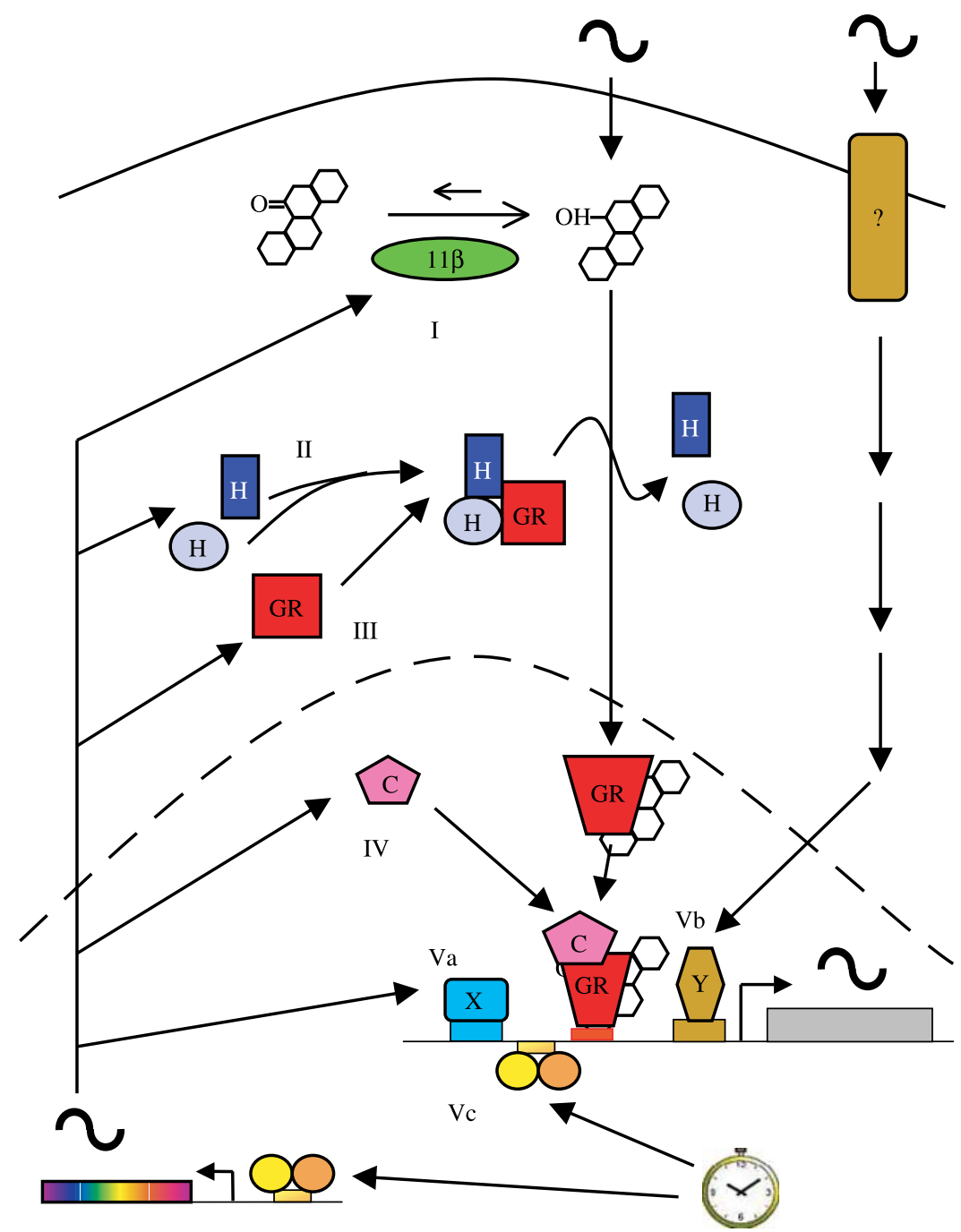

Figure 5 Hypothetical intracellular mechanisms of circadian modulation of glucocorticoid signalling. I) HSD11B1 (11 $\beta$, green) catalyses conversion of inactive keto-

glucocorticoids $(\mathrm{O}=)$ to their active hydroxyforms $(\mathrm{OH}-)$. Its mRNA is under circadian regulation in certain tissues. II) Heat shock proteins (HSPs, H, blue) form complexes with the glucocorticoid receptor (GR, red) in the cytoplasm, before GR binding of glucocorticoids and subsequent nuclear translocation. Expression of many HSPs shows circadian dynamics. III) The mRNA of the GR itself shows circadian cycling in some tissues. IV) Transcriptional cofactors (C, pink) for nuclear receptors, such as PGC1 $\alpha$, can be regulated in a circadian fashion. $\mathrm{V}$ ) The glucocorticoid receptor can interact with various signalling pathways at the level of the promoter of its target genes. This may include: $\mathrm{Va}$ ) other transcription factors which are subject to circadian regulation at the level of their mRNAs (X, turquoise, e.g. HNF4A), Vb) targets of other signalling pathways subject to circadian changes in their activity ( $\mathrm{Y}$, brown) and $\mathrm{Vc}_{\mathrm{C}}$ ) the core clock components themselves (yellow and orange, Fig. 1).

these pulsatile dynamics. Interestingly, a proteasome-dependent mechanism has recently been described that contributes to shutting off GR signalling at the trough of the glucocorticoid pulses (Conway-Campbell et al. 2007, Lightman et al. 2008), and one could speculate that circadian and ultradian rhythms might interact via such posttranslational mechanisms.
A second topic with need for further research is the establishment of the various dynamic regulations of glucocorticoid release during development. This is of importance, as prenatal stress or metabolic state of the mother can influence physiology and disease risk of the child, perhaps even into the next generation (Remacle et al. 2007, Darnaudery \& Maccari 2008, Seckl 2008). It will be 
informative to determine whether and to what extent such developmental programming acts via changes in the circadian rhythmicity of the HPA axis and glucocorticoid release.

This leads us to a third topic. How precisely do changes in the circadian regulation of corticosteroids contribute to pathology? In many diseases, including Cushing's syndrome, depression, Alzheimer's disease and the metabolic syndrome, circadian glucocorticoid regulation is altered (Ferrari et al. 2001, Pasquali et al. 2006, Bao et al. 2008, Carroll et al. 2008). It will be important to know in which cases these changes are a mere symptom of the disease and in which cases they are a causal factor for the development of the disease. This information might then be translated into more physiological and more efficient therapies.

\section{Declaration of interest}

The author declares that there is no conflict of interest that could be perceived as prejudicing the impartiality of the research reported.

\section{Funding}

This research did not receive any specific grant from any funding agency in the public, commercial or not-for-profit sector.

\section{Acknowledgements}

I thank Andrew Cato, Nicholas Foulkes and Olivier Kassel for critical comments on previous versions of this manuscript.

\section{References}

Abdel-Malek ZA 2001 Melanocortin receptors: their functions and regulation by physiological agonists and antagonists. Cellular and Molecular Life Sciences 58 434-441.

Abe K, Kroning J, Greer MA \& Critchlow V 1979 Effects of destruction of the suprachiasmatic nuclei on the circadian rhythms in plasma corticosterone, body temperature, feeding and plasma thyrotropin. Neuroendocrinology 29 119-131.

Abe M, Herzog ED, Yamazaki S, Straume M, Tei H, Sakaki Y, Menaker M \& Block GD 2002 Circadian rhythms in isolated brain regions. Journal of Neuroscience 22 350-356.

Akhtar RA, Reddy AB, Maywood ES, Clayton JD, King VM, Smith AG, Gant TW, Hastings MH \& Kyriacou CP 2002 Circadian cycling of the mouse liver transcriptome, as revealed by cDNA microarray, is driven by the suprachiasmatic nucleus. Current Biology 12 540-550.

Almon RR, Yang E, Lai W, Androulakis IP, Ghimbovschi S, Hoffman EP, Jusko WJ \& Dubois DC 2008 Relationships between circadian rhythms and modulation of gene expression by glucocorticoids in skeletal muscle. American Journal of Physiology. Regulatory, Integrative and Comparative Physiology 295 R1031-R1047.

Amir S \& Robinson B 2006 Thyroidectomy alters the daily pattern of expression of the clock protein, PER2, in the oval nucleus of the bed nucleus of the stria terminalis and central nucleus of the amygdala in rats. Neuroscience Letters 407 254-257.

Amir S, Lamont EW, Robinson B \& Stewart J 2004 A circadian rhythm in the expression of PERIOD2 protein reveals a novel SCN-controlled oscillator in the oval nucleus of the bed nucleus of the stria terminalis. Journal of Neuroscience 24 781-790.
Andrews RV 1971 Circadian rhythms in adrenal organ cultures. Gegenbaurs Morphologisches Jahrbuch 117 89-98.

Andrews RV \& Folk GE Jr 1964 Circadian metabolic patterns in cultured hamster adrenal glands. Comparative Biochemistry and Physiology 11 393-409.

Antle MC \& Silver R 2005 Orchestrating time: arrangements of the brain circadian clock. Trends in Neurosciences 28 145-151.

Antoni FA, Palkovits M, Makara GB, Linton EA, Lowry PJ \& Kiss JZ 1983 Immunoreactive corticotropin-releasing hormone in the hypothalamoinfundibular tract. Neuroendocrinology 36 415-423.

Arriza JL, Simerly RB, Swanson LW \& Evans RM 1988 The neuronal mineralocorticoid receptor as a mediator of glucocorticoid response. Neuron $1887-900$.

Aschoff J 1979 Circadian rhythms: general features and endocrinological aspects. In Endocrine Rhythms, pp 1-63. Ed. D Krieger. New York: Raven Press.

Atkinson HC, Wood SA, Kershaw YM, Bate E \& Lightman SL 2006 Diurnal variation in the responsiveness of the hypothalamic-pituitary-adrenal axis of the male rat to noise stress. Journal of Neuroendocrinology 18 526-533.

Balsalobre A 2002 Clock genes in mammalian peripheral tissues. Cell and Tissue Research 309 193-199.

Balsalobre A, Damiola F \& Schibler U 1998 A serum shock induces circadian gene expression in mammalian tissue culture cells. Cell 93 929-937.

Balsalobre A, Brown SA, Marcacci L, Tronche F, Kellendonk C, Reichardt HM, Schutz G \& Schibler U 2000 Resetting of circadian time in peripheral tissues by glucocorticoid signaling. Science 289 2344-2347.

Bao AM, Meynen G \& Swaab DF 2008 The stress system in depression and neurodegeneration: focus on the human hypothalamus. Brain Research Reviews $\mathbf{5 7}$ 531-553.

Berk ML \& Finkelstein JA 1981 An autoradiographic determination of the efferent projections of the suprachiasmatic nucleus of the hypothalamus. Brain Research 226 1-13.

Berson DM 2007 Phototransduction in ganglion-cell photoreceptors. Pflügers Archiv 454 849-855.

Bertolucci C, Cavallari N, Colognesi I, Aguzzi J, Chen Z, Caruso P, Fo A, Tosini G, Bernardi F \& Pinotti M 2008 Evidence for an overlapping role of CLOCK and NPAS2 transcription factors in liver circadian oscillators. Molecular and Cellular Biology 28 3070-3075.

Bittman EL, Doherty L, Huang L \& Paroskie A 2003 Period gene expression in mouse endocrine tissues. American Journal of Physiology. Regulatory, Integrative and Comparative Physiology 285 R 561-R569.

Bjarnason GA \& Jordan R 2000 Circadian variation of cell proliferation and cell cycle protein expression in man: clinical implications. Progress in Cell Cycle Research 4 193-206.

Bornstein SR, Ehrhart-Bornstein M, Scherbaum WA, Pfeiffer EF \& Holst JJ 1990 Effects of splanchnic nerve stimulation on the adrenal cortex may be mediated by chromaffin cells in a paracrine manner. Endocrinology 127 900-906.

Bornstein SR, Engeland WC, Ehrhart-Bornstein M \& Herman JP 2008 Dissociation of ACTH and glucocorticoids. Trends in Endocrinology and Metabolism 19 175-180.

Bozek K, Kielbasa SM, Kramer A \& Herzel H 2007 Promoter analysis of mammalian clock controlled genes. Genome Informatics 18 65-74.

Brown MR \& Fisher LA 1986 Glucocorticoid suppression of the sympathetic nervous system and adrenal medulla. Life Sciences 39 1003-1012.

Brown SA, Zumbrunn G, Fleury-Olela F, Preitner N \& Schibler U 2002 Rhythms of mammalian body temperature can sustain peripheral circadian clocks. Current Biology 12 1574-1583.

Brunner M \& Schafmeier T 2006 Transcriptional and post-transcriptional regulation of the circadian clock of cyanobacteria and Neurospora. Genes and Development 20 1061-1074.

Brunner M, Simons MJ \& Merrow M 2008 Lego clocks: building a clock from parts. Genes and Development 22 1422-1426.

Buijs RM \& Escobar C 2007 Corticosterone and activity: the long arms of the clock talk back. Endocrinology 148 5162-5164.

Buijs RM \& Kalsbeek A 2001 Hypothalamic integration of central and peripheral clocks. Nature Reviews. Neuroscience 2 521-526. 
Buijs RM, Kalsbeek A, van der Woude TP, van Heerikhuize JJ \& Shinn S 1993 a Suprachiasmatic nucleus lesion increases corticosterone secretion. American Journal of Physiology 264 R1186-R1192.

Buijs RM, Markman M, Nunes-Cardoso B, Hou YX \& Shinn S $1993 b$ Projections of the suprachiasmatic nucleus to stress-related areas in the rat hypothalamus: a light and electron microscopic study. Journal of Comparative Neurology 335 42-54.

Buijs RM, Wortel J, Van Heerikhuize JJ, Feenstra MG, Ter Horst GJ, Romijn HJ \& Kalsbeek A 1999 Anatomical and functional demonstration of a multisynaptic suprachiasmatic nucleus adrenal (cortex) pathway. European Journal of Neuroscience 11 1535-1544.

Buijs RM, van Eden CG, Goncharuk VD \& Kalsbeek A 2003 The biological clock tunes the organs of the body: timing by hormones and the autonomic nervous system. Journal of Endocrinology 177 17-26.

Buren J, Bergstrom SA, Loh E, Soderstrom I, Olsson T \& Mattsson C 2007 Hippocampal 11beta-hydroxysteroid dehydrogenase type 1 messenger ribonucleic acid expression has a diurnal variability that is lost in the obese Zucker rat. Endocrinology 148 2716-2722.

Busino L, Bassermann F, Maiolica A, Lee C, Nolan PM, Godinho SI, Draetta GF \& Pagano M 2007 SCFFbxl3 controls the oscillation of the circadian clock by directing the degradation of cryptochrome proteins. Science $\mathbf{3 1 6}$ 900-904.

Cailotto C, La Fleur SE, Van Heijningen C, Wortel J, Kalsbeek A, Feenstra M, Pevet P \& Buijs RM 2005 The suprachiasmatic nucleus controls the daily variation of plasma glucose via the autonomic output to the liver: are the clock genes involved? European Journal of Neuroscience $\mathbf{2 2}$ 2531-2540

Cailotto C, van Heijningen C, van der Vliet J, van der Plasse G, Habold C, Kalsbeek A, Pevet P \& Buijs RM 2008 Daily rhythms in metabolic liver enzymes and plasma glucose require a balance in the autonomic output to the liver. Endocrinology 149 1914-1925.

Carnes M, Kalin NH, Lent SJ, Barksdale CM \& Brownfield MS 1988 Pulsatile ACTH secretion: variation with time of day and relationship to cortisol. Peptides 9 325-331.

Carnes M, Lent S, Feyzi J \& Hazel D 1989 Plasma adrenocorticotropic hormone in the rat demonstrates three different rhythms within $24 \mathrm{~h}$. Neuroendocrinology 50 17-25.

Carr AJ \& Whitmore D 2005 Imaging of single light-responsive clock cells reveals fluctuating free-running periods. Nature Cell Biology 7 319-321.

Carroll T, Raff H \& Findling JW 2008 Late-night salivary cortisol measurement in the diagnosis of Cushing's syndrome. Nature Clinical Practice. Endocrinology \& Metabolism 4 344-350.

Cascio CS, Shinsako J \& Dallman MF 1987 The suprachiasmatic nuclei stimulate evening ACTH secretion in the rat. Brain Research 423 173-178.

Van Cauter E 1990 Diurnal and ultradian rhythms in human endocrine function: a minireview. Hormone Research 34 45-53.

Chapman KE \& Seckl JR 2008 11ß-HSD1, inflammation, metabolic disease and age-related cognitive (dys)function. Neurochemistry Research 33 624-636.

Cheifetz PN 1971 The daily rhythm of the secretion of corticotrophin and corticosterone in rats and mice. Journal of Endocrinology 49 xi-xii.

Chrousos GP 1998 Ultradian, circadian, and stress-related hypothalamicpituitary-adrenal axis activity - a dynamic digital-to-analog modulation. Endocrinology 139 437-440.

Claridge-Chang A, Wijnen H, Naef F, Boothroyd C, Rajewsky N \& Young MW 2001 Circadian regulation of gene expression systems in the Drosophila head. Neuron 32 657-671.

Conway-Campbell BL, McKenna MA, Wiles CC, Atkinson HC, de Kloet ER \& Lightman SL 2007 Proteasome-dependent down-regulation of activated nuclear hippocampal glucocorticoid receptors determines dynamic responses to corticosterone. Endocrinology 148 5470-5477.

Dallman MF, Engeland WC, Rose JC, Wilkinson CW, Shinsako J \& Siedenburg F 1978 Nycthemeral rhythm in adrenal responsiveness to ACTH. American Journal of Physiology 235 R210-R218.

Dallman MF, Strack AM, Akana SF, Bradbury MJ, Hanson ES, Scribner KA \& Smith M 1993 Feast and famine: critical role of glucocorticoids with insulin in daily energy flow. Frontiers in Neuroendocrinology 14 303-347.
Damiola F, Le Minh N, Preitner N, Kornmann B, Fleury-Olela F \& Schibler U 2000 Restricted feeding uncouples circadian oscillators in peripheral tissues from the central pacemaker in the suprachiasmatic nucleus. Genes and Development 14 2950-2961.

Darnaudery M \& Maccari S 2008 Epigenetic programming of the stress response in male and female rats by prenatal restraint stress. Brain Research Reviews $\mathbf{5 7}$ 571-585.

Davidson AJ 2006 Search for the feeding-entrainable circadian oscillator: a complex proposition. American Journal of Physiology. Regulatory, Integrative and Comparative Physiology 290 R1524-R1526.

Debruyne JP, Noton E, Lambert CM, Maywood ES, Weaver DR \& Reppert SM 2006 A clock shock: mouse CLOCK is not required for circadian oscillator function. Neuron $50465-477$.

DeBruyne JP, Weaver DR \& Reppert SM 2007a Peripheral circadian oscillators require CLOCK. Current Biology 17 R538-R539.

DeBruyne JP, Weaver DR \& Reppert SM $2007 b$ CLOCK and NPAS2 have overlapping roles in the suprachiasmatic circadian clock. Nature Neuroscience $10543-545$.

Dekens MP, Santoriello C, Vallone D, Grassi G, Whitmore D \& Foulkes NS 2003 Light regulates the cell cycle in zebrafish. Current Biology 13 2051-2057.

Dickmeis T, Lahiri K, Nica G, Vallone D, Santoriello C, Neumann CJ, Hammerschmidt M \& Foulkes NS 2007 Glucocorticoids play a key role in circadian cell cycle rhythms. PLoS Biology 5 e78.

Dijkstra I, Binnekade R \& Tilders FJ 1996 Diurnal variation in resting levels of corticosterone is not mediated by variation in adrenal responsiveness to adrenocorticotropin but involves splanchnic nerve integrity. Endocrinology $137540-547$.

Dudley CA, Erbel-Sieler C, Estill SJ, Reick M, Franken P, Pitts S \& McKnight SL 2003 Altered patterns of sleep and behavioral adaptability in NPAS2deficient mice. Science 301 379-383.

Duez H \& Staels B 2008 The nuclear receptors Rev-erbs and RORs integrate circadian rhythms and metabolism. Diabetes $\&$ Vascular Disease Research 5 82-88.

Duffield GE 2003 DNA microarray analyses of circadian timing: the genomic basis of biological time. Journal of Neuroendocrinology 15 991-1002.

Dunlap J, Loros J \& DeCoursey P 2004 Chronobiology., Sunderland: Sinauer Associates.

Ehrhart-Bornstein M, Hinson JP, Bornstein SR, Scherbaum WA \& Vinson GP 1998 Intraadrenal interactions in the regulation of adrenocortical steroidogenesis. Endocrine Reviews 19 101-143.

Engeland WC \& Arnhold MM 2005 Neural circuitry in the regulation of adrenal corticosterone rhythmicity. Endocrine 28 325-332.

Engler D, Pham T, Fullerton MJ, Ooi G, Funder JW \& Clarke IJ 1989 Studies of the secretion of corticotropin-releasing factor and arginine vasopressin into the hypophysial-portal circulation of the conscious sheep. I. Effect of an audiovisual stimulus and insulin-induced hypoglycemia. Neuroendocrinology 49 367-381.

Fahrenkrug J, Hannibal J \& Georg B 2008 Diurnal rhythmicity of the canonical clock genes Per1, Per2 and Bmal1 in the rat adrenal gland is unaltered after hypophysectomy. Journal of Neuroendocrinology 20 323-329.

Falvey E, Fleury-Olela F \& Schibler U 1995 The rat hepatic leukemia factor (HLF) gene encodes two transcriptional activators with distinct circadian rhythms, tissue distributions and target preferences. EMBO Journal 14 4307-4317.

Feillet CA, Ripperger JA, Magnone MC, Dulloo A, Albrecht U \& Challet E 2006 Lack of food anticipation in Per2 mutant mice. Current Biology 16 2016-2022.

Ferrari E, Casarotti D, Muzzoni B, Albertelli N, Cravello L, Fioravanti M, Solerte SB \& Magri F 2001 Age-related changes of the adrenal secretory pattern: possible role in pathological brain aging. Brain Research. Brain Research Reviews 37 294-300.

Fonjallaz P, Ossipow V, Wanner G \& Schibler U 1996 The two PAR leucine zipper proteins, TEF and DBP, display similar circadian and tissue-specific expression, but have different target promoter preferences. EMBO Journal 15 351-362.

Fuller PM, Lu J \& Saper CB 2008 Differential rescue of light- and foodentrainable circadian rhythms. Science 320 1074-1077. 
Furay AR, Murphy EK, Mattson MP, Guo Z \& Herman JP 2006 Regionspecific regulation of glucocorticoid receptor/HSP90 expression and interaction in brain. Journal of Neurochemistry 98 1176-1184.

Gallego M \& Virshup DM 2007 Post-translational modifications regulate the ticking of the circadian clock. Nature Reviews. Molecular Cell Biology 8 139-148.

Van Gelder RN, Bae H, Palazzolo MJ \& Krasnow MA 1995 Extent and character of circadian gene expression in Drosophila melanogaster: identification of twenty oscillating mRNAs in the fly head. Current Biology $\mathbf{5}$ 1424-1436.

Godinho SI, Maywood ES, Shaw L, Tucci V, Barnard AR, Busino L, Pagano M, Kendall R, Quwailid MM, Romero MR et al. 2007 The after-hours mutant reveals a role for Fbxl3 in determining mammalian circadian period. Science 316 897-900.

Gooley JJ \& Saper CB 2007 Is food-directed behavior an appropriate measure of circadian entrainment to restricted daytime feeding? Journal of Biological Rhythms 22 479-483 (discussion 484-487).

Gooley JJ, Schomer A \& Saper CB 2006 The dorsomedial hypothalamic nucleus is critical for the expression of food-entrainable circadian rhythms. Nature Neuroscience 9 398-407.

Grad I \& Picard D 2007 The glucocorticoid responses are shaped by molecular chaperones. Molecular and Cellular Endocrinology 275 2-12.

Graham ES, Littlewood P, Turnbull Y, Mercer JG, Morgan PJ \& Barrett P 2005 Neuromedin-U is regulated by the circadian clock in the SCN of the mouse. European Journal of Neuroscience 21 814-819.

Gudmundsson A \& Carnes M 1997 Pulsatile adrenocorticotropic hormone: an overview. Biological Psychiatry 41 342-365.

Gummow BM, Scheys JO, Cancelli VR \& Hammer GD 2006 Reciprocal regulation of a glucocorticoid receptor-steroidogenic factor-1 transcription complex on the Dax-1 promoter by glucocorticoids and adrenocorticotropic hormone in the adrenal cortex. Molecular Endocrinology 20 2711-2723.

Hankins MW, Peirson SN \& Foster RG 2008 Melanopsin: an exciting photopigment. Trends in Neurosciences $3127-36$.

Hara R, Wan K, Wakamatsu H, Aida R, Moriya T, Akiyama M \& Shibata S 2001 Restricted feeding entrains liver clock without participation of the suprachiasmatic nucleus. Genes to Cells 6 269-278.

De Haro L \& Panda S 2006 Systems biology of circadian rhythms: an outlook. Journal of Biological Rhythms 21 507-518.

Harris HJ, Kotelevtsev Y, Mullins JJ, Seckl JR \& Holmes MC 2001 Intracellular regeneration of glucocorticoids by 11beta-hydroxysteroid dehydrogenase (11beta-HSD)-1 plays a key role in regulation of the hypothalamic-pituitary-adrenal axis: analysis of 11beta-HSD-1-deficient mice. Endocrinology 142 114-120.

Hastings M, O'Neill JS \& Maywood ES 2007 Circadian clocks: regulators of endocrine and metabolic rhythms. Journal of Endocrinology 195 187-198.

Haus E 2007 Chronobiology in the endocrine system. Advanced Drug Delivery Reviews 59 985-1014.

Herman JP, Watson SJ, Chao HM, Coirini H \& McEwen BS 1993 Diurnal regulation of glucocorticoid receptor and mineralocorticoid receptor mRNAs in rat hippocampus. Molecular and Cellular Neurosciences 4 181-190.

Herzog ED \& Muglia LJ 2006 You are when you eat. Nature Neuroscience 9 300-302.

Hiroshige T, Honma K \& Honma S 1991 SCN-independent circadian oscillators in the rat. Brain Research Bulletin 27 441-445.

Holaday JW, Martinez HM \& Natelson BH 1977 Synchronized ultradian cortisol rhythms in monkeys: persistence during corticotropin infusion. Science 198 56-58.

ter Horst GJ \& Luiten PG 1986 The projections of the dorsomedial hypothalamic nucleus in the rat. Brain Research Bulletin 16 231-248.

Hunt T \& Sassone-Corsi P 2007 Riding tandem: circadian clocks and the cell cycle. Cell 129 461-464.

Iijima M, Yamaguchi S, van der Horst GT, Bonnefont X, Okamura H \& Shibata S 2005 Altered food-anticipatory activity rhythm in cryptochromedeficient mice. Neuroscience Research 52 166-173.

Irvine CH \& Alexander SL 1994 Factors affecting the circadian rhythm in plasma cortisol concentrations in the horse. Domestic Animal Endocrinology $11227-238$.
Ishida A, Mutoh T, Ueyama T, Bando H, Masubuchi S, Nakahara D, Tsujimoto G \& Okamura H 2005 Light activates the adrenal gland: timing of gene expression and glucocorticoid release. Cell Metabolism 2 297-307.

Jacobson L 2005 Hypothalamic-pituitary-adrenocortical axis regulation. Endocrinology and Metabolism Clinics of North America 34 271-292 (vii).

Jasper MS \& Engeland WC 1991 Synchronous ultradian rhythms in adrenocortical secretion detected by microdialysis in awake rats. American Journal of Physiology 261 R1257-R1268.

Joels M, Karst H, DeRijk R \& de Kloet ER 2008 The coming out of the brain mineralocorticoid receptor. Trends in Neurosciences 31 1-7.

Kadener S, Menet JS, Schoer R \& Rosbash M 2008 Circadian transcription contributes to core period determination in Drosophila. PLoS Biology 6 e119.

Kalsbeek A \& Buijs RM 2002 Output pathways of the mammalian suprachiasmatic nucleus: coding circadian time by transmitter selection and specific targeting. Cell and Tissue Research 309 109-118.

Kalsbeek A, Buijs RM, van Heerikhuize JJ, Arts M \& van der Woude TP 1992 Vasopressin-containing neurons of the suprachiasmatic nuclei inhibit corticosterone release. Brain Research 580 62-67.

Kalsbeek A, Buijs RM, Engelmann M, Wotjak CT \& Landgraf R 1995 In vivo measurement of a diurnal variation in vasopressin release in the rat suprachiasmatic nucleus. Brain Research 682 75-82.

Kalsbeek A, van der Vliet J \& Buijs RM 1996a Decrease of endogenous vasopressin release necessary for expression of the circadian rise in plasma corticosterone: a reverse microdialysis study. Journal of Neuroendocrinology $\mathbf{8}$ 299-307.

Kalsbeek A, van Heerikhuize JJ, Wortel J \& Buijs RM 1996 b A diurnal rhythm of stimulatory input to the hypothalamo-pituitary-adrenal system as revealed by timed intrahypothalamic administration of the vasopressin $\mathrm{V} 1$ antagonist. Journal of Neuroscience 16 5555-5565.

Kalsbeek A, Ruiter M, La Fleur SE, Van Heijningen C \& Buijs RM 2003 The diurnal modulation of hormonal responses in the rat varies with different stimuli. Journal of Neuroendocrinology 15 1144-1155.

Kalsbeek A, Palm IF, La Fleur SE, Scheer FA, Perreau-Lenz S, Ruiter M, Kreier F, Cailotto C \& Buijs RM 2006 SCN outputs and the hypothalamic balance of life. Journal of Biological Rhythms 21 458-469.

Kalsbeek A, Verhagen LA, Schalij I, Foppen E, Saboureau M, Bothorel B, Buijs RM \& Pevet P 2008 Opposite actions of hypothalamic vasopressin on circadian corticosterone rhythm in nocturnal versus diurnal species. European Journal of Neuroscience 27 818-827.

Kaneko M, Hernandez-Borsetti N \& Cahill GM 2006 Diversity of zebrafish peripheral oscillators revealed by luciferase reporting. PNAS 103 14614-14619.

Kassahn KS, Crozier RH, Ward AC, Stone G \& Caley MJ 2007 From transcriptome to biological function: environmental stress in an ectothermic vertebrate, the coral reeffish Pomacentrus moluccensis. BMC Genomics 8358.

Kassel O \& Herrlich P 2007 Crosstalk between the glucocorticoid receptor and other transcription factors: molecular aspects. Molecular and Cellular Endocrinology 275 13-29.

Keegan KP, Pradhan S, Wang JP \& Allada R 2007 Meta-analysis of Drosophila circadian microarray studies identifies a novel set of rhythmically expressed genes. PLoS Computational Biology 3 e208.

Kennaway DJ, Owens JA, Voultsios A \& Varcoe TJ 2006 Functional central rhythmicity and light entrainment, but not liver and muscle rhythmicity, are Clock independent. American Journal of Physiology. Regulatory, Integrative and Comparative Physiology 291 R1172-R1180.

Kitayama Y, Nishiwaki T, Terauchi K \& Kondo T 2008 Dual KaiC-based oscillations constitute the circadian system of cyanobacteria. Genes and Development 22 1513-1521.

Klein DC, Moore RY \& Reppert SM 1991 Suprachiasmatic Nucleus - The Mind's Clock. New York: Oxford University Press.

Klemcke HG, Nienaber JA \& Hahn GL 1989 Plasma adrenocorticotropic hormone and cortisol in pigs: effects of time of day on basal and stressoraltered concentrations. Proceedings of the Society for Experimental Biology and Medicine 190 42-53. 
Knutti D, Kaul A \& Kralli A 2000 A tissue-specific coactivator of steroid receptors, identified in a functional genetic screen. Molecular and Cellular Biology 20 2411-2422.

Ko CH \& Takahashi JS 2006 Molecular components of the mammalian circadian clock. Human Molecular Genetics 15 R271-R277.

Kornmann B, Schaad O, Bujard H, Takahashi JS \& Schibler U 2007 Systemdriven and oscillator-dependent circadian transcription in mice with a conditionally active liver clock. PLoS Biology 5 e34.

Krieger DT, Hauser H \& Krey LC 1977 Suprachiasmatic nuclear lesions do not abolish food-shifted circadian adrenal and temperature rhythmicity. Science 197 398-399.

Lamont EW, Robinson B, Stewart J \& Amir S 2005 The central and basolateral nuclei of the amygdala exhibit opposite diurnal rhythms of expression of the clock protein Period2. PNAS 102 4180-4184.

Landry GJ \& Mistlberger RE 2007 Food entrainment: methodological issues. Journal of Biological Rhythms 22 484-487.

Landry GJ, Simon MM, Webb IC \& Mistlberger RE 2006 Persistence of a behavioral food-anticipatory circadian rhythm following dorsomedial hypothalamic ablation in rats. American Journal of Physiology. Regulatory, Integrative and Comparative Physiology 290 R1527-R1534.

Landry GJ, Yamakawa GR, Webb IC, Mear RJ \& Mistlberger RE 2007 The dorsomedial hypothalamic nucleus is not necessary for the expression of circadian food-anticipatory activity in rats. Journal of Biological Rhythms $\mathbf{2 2}$ 467-478.

Lefcourt AM, Bitman J, Kahl S \& Wood DL 1993 Circadian and ultradian rhythms of peripheral cortisol concentrations in lactating dairy cows. Journal of Dairy Science 76 2607-2612.

Lemos DR, Downs JL \& Urbanski HF 2006 Twenty-four-hour rhythmic gene expression in the rhesus macaque adrenal gland. Molecular Endocrinology 20 1164-1176.

Lightman SL 2008 The neuroendocrinology of stress: a never ending story. Journal of Neuroendocrinology 20 880-884.

Lightman SL, Wiles CC, Atkinson HC, Henley DE, Russell GM, Leendertz JA, McKenna MA, Spiga F, Wood SA \& Conway-Campbell BL 2008 The significance of glucocorticoid pulsatility. European Journal of Pharmacology $583255-262$.

Lincoln GA, Almeida OF, Klandorf H \& Cunningham RA 1982 Hourly fluctuations in the blood levels of melatonin, prolactin, luteinizing hormone, follicle-stimulating hormone, testosterone, tri-iodothyronine, thyroxine and cortisol in rams under artificial photoperiods, and the effects of cranial sympathectomy. Journal of Endocrinology 92 237-250.

Liu Y, Tsinoremas NF, Johnson CH, Lebedeva NV, Golden SS, Ishiura M \& Kondo T 1995 Circadian orchestration of gene expression in cyanobacteria. Genes and Development 9 1469-1478.

Liu C, Li S, Liu T, Borjigin J \& Lin JD 2007 Transcriptional coactivator PGC1alpha integrates the mammalian clock and energy metabolism. Nature $\mathbf{4 4 7}$ 477-481.

Loudon AS, Wayne NL, Krieg R, Iranmanesh A, Veldhuis JD \& Menaker M 1994 Ultradian endocrine rhythms are altered by a circadian mutation in the Syrian hamster. Endocrinology 135 712-718.

Lowry CA 2002 Functional subsets of serotonergic neurones: implications for control of the hypothalamic-pituitary-adrenal axis. Journal of Neuroendocrinology 14 911-923.

Mackey SR \& Golden SS 2007 Winding up the cyanobacterial circadian clock. Trends in Microbiology 15 381-388.

Malek ZS, Sage D, Pevet P \& Raison S 2007 Daily rhythm of tryptophan hydroxylase-2 messenger ribonucleic acid within raphe neurons is induced by corticoid daily surge and modulated by enhanced locomotor activity. Endocrinology 148 5165-5172.

Matsuo T, Yamaguchi S, Mitsui S, Emi A, Shimoda F \& Okamura H 2003 Control mechanism of the circadian clock for timing of cell division in vivo. Science 302 255-259.

Maywood ES, O'Neill JS, Chesham JE \& Hastings MH 2007 Minireview: the circadian clockwork of the suprachiasmatic nuclei - analysis of a cellular oscillator that drives endocrine rhythms. Endocrinology 148 5624-5634.

McDonald MJ \& Rosbash M 2001 Microarray analysis and organization of circadian gene expression in Drosophila. Cell 107 567-578.
Meier AH 1976 Daily variation in concentration of plasma corticosteroid in hypophysectomized rats. Endocrinology 98 1475-1479.

Menaker M, Moreira LF \& Tosini G 1997 Evolution of circadian organization in vertebrates. Brazilian Journal of Medical and Biological Research 30 305-313.

Mendoza J 2007 Circadian clocks: setting time by food. Journal of Neuroendocrinology 19 127-137.

Meyer-Bernstein EL \& Morin LP 1999 Electrical stimulation of the median or dorsal raphe nuclei reduces light-induced FOS protein in the suprachiasmatic nucleus and causes circadian activity rhythm phase shifts. Neuroscience 92 267-279.

Meyer-Bernstein EL, Jetton AE, Matsumoto SI, Markuns JF, Lehman MN \& Bittman EL 1999 Effects of suprachiasmatic transplants on circadian rhythms of neuroendocrine function in golden hamsters. Endocrinology 140 207-218.

Mieda M, Williams SC, Richardson JA, Tanaka K \& Yanagisawa M 2006 The dorsomedial hypothalamic nucleus as a putative food-entrainable circadian pacemaker. PNAS 103 12150-12155.

Le Minh N, Damiola F, Tronche F, Schutz G \& Schibler U 2001 Glucocorticoid hormones inhibit food-induced phase-shifting of peripheral circadian oscillators. EMBO Journal 20 7128-7136.

Mistlberger RE 1994 Circadian food-anticipatory activity: formal models and physiological mechanisms. Neuroscience and Biobehavioral Reviews $\mathbf{1 8}$ 171-195.

Moore RY \& Eichler VB 1972 Loss of a circadian adrenal corticosterone rhythm following suprachiasmatic lesions in the rat. Brain Research $\mathbf{4 2}$ 201-206.

Mori T \& Johnson CH 2000 Circadian control of cell division in unicellular organisms. Progress in Cell Cycle Research 4 185-192.

Morin LP 1999 Serotonin and the regulation of mammalian circadian rhythmicity. Annals of Medicine 31 12-33.

Nagoshi E, Saini C, Bauer C, Laroche T, Naef F \& Schibler U 2004 Circadian gene expression in individual fibroblasts: cell-autonomous and selfsustained oscillators pass time to daughter cells. Cell 119 693-705.

Nakajima M, Imai K, Ito H, Nishiwaki T, Murayama Y, Iwasaki H, Oyama T \& Kondo T 2005 Reconstitution of circadian oscillation of cyanobacterial KaiC phosphorylation in vitro. Science 308 414-415.

Niijima A, Nagai K, Nagai N \& Nakagawa H 1992 Light enhances sympathetic and suppresses vagal outflows and lesions including the suprachiasmatic nucleus eliminate these changes in rats. Journal of the Autonomic Nervous System 40 155-160.

Niijima A, Nagai K, Nagai N \& Akagawa H 1993 Effects of light stimulation on the activity of the autonomic nerves in anesthetized rats. Physiology and Behavior 54 555-561.

Norris DO 2007 Vertebrate Endocrinology. 4 edn, Burlington, San Diego, London: Elsevier Academic Press.

Oishi K, Fukui H \& Ishida N 2000 Rhythmic expression of BMAL1 mRNA is altered in Clock mutant mice: differential regulation in the suprachiasmatic nucleus and peripheral tissues. Biochemical and Biophysical Research Communications 268 164-171.

Oishi K, Amagai N, Shirai H, Kadota K, Ohkura N \& Ishida N 2005 Genome-wide expression analysis reveals 100 adrenal gland-dependent circadian genes in the mouse liver. DNA Research 12 191-202.

Oster H, Damerow S, Hut RA \& Eichele G 2006a Transcriptional profiling in the adrenal gland reveals circadian regulation of hormone biosynthesis genes and nucleosome assembly genes. Journal of Biological Rhythms 21 350-361.

Oster H, Damerow S, Kiessling S, Jakubcakova V, Abraham D, Tian J, Hoffmann MW \& Eichele G $2006 b$ The circadian rhythm of glucocorticoids is regulated by a gating mechanism residing in the adrenal cortical clock. Cell Metabolism 4 163-173.

Ottenweller JE \& Meier AH 1982 Adrenal innervation may be an extrapituitary mechanism able to regulate adrenocortical rhythmicity in rats. Endocrinology 111 1334-1338.

Panda S, Antoch M, Miller B, Su A, Schook A, Straume M, Schultz P, Kay S, Takahashi J \& Hogenesch J 2002 Coordinated transcription of key pathways in the mouse by the circadian clock. Cell 109 307-320. 
Pasquali R, Vicennati V, Cacciari M \& Pagotto U 2006 The hypothalamicpituitary-adrenal axis activity in obesity and the metabolic syndrome. Annals of the New York Academy of Sciences 1083 111-128.

Paterson JM, Holmes MC, Kenyon CJ, Carter R, Mullins JJ \& Seckl JR 2007 Liver-selective transgene rescue of hypothalamic-pituitary-adrenal axis dysfunction in 11beta-hydroxysteroid dehydrogenase type 1-deficient mice. Endocrinology 148 961-966.

Payne AH \& Hales DB 2004 Overview of steroidogenic enzymes in the pathway from cholesterol to active steroid hormones. Endocrine Reviews $\mathbf{2 5}$ 947-970.

Pecoraro N, Dallman MF, Warne JP, Ginsberg AB, Laugero KD, la Fleur SE, Houshyar H, Gomez F, Bhargava A \& Akana SF 2006 From Malthus to motive: how the HPA axis engineers the phenotype, yoking needs to wants. Progress in Neurobiology 79 247-340.

Perlow MJ, Reppert SM, Boyar RM \& Klein DC 1981 Daily rhythms in cortisol and melatonin in primate cerebrospinal fluid. Effects of constant light and dark. Neuroendocrinology 32 193-196.

Perrin JS, Segall LA, Harbour VL, Woodside B \& Amir S 2006 The expression of the clock protein PER2 in the limbic forebrain is modulated by the estrous cycle. PNAS 103 5591-5596.

Pitts S, Perone E \& Silver R 2003 Food-entrained circadian rhythms are sustained in arrhythmic Clk/Clk mutant mice. American Journal of Physiology. Regulatory, Integrative and Comparative Physiology 285 R57-R67.

Reddy AB \& Maywood ES 2007 Circadian rhythms: per2bations in the liver clock. Current Biology 17 R292-R294.

Reddy AB, Wong GK, O'Neill J, Maywood ES \& Hastings MH 2005 Circadian clocks: neural and peripheral pacemakers that impact upon the cell division cycle. Mutation Research $\mathbf{5 7 4}$ 76-91.

Reddy AB, Karp NA, Maywood ES, Sage EA, Deery M, O’Neill JS, Wong GKY, Chesham J, Odell M, Lilley KS et al. 2006 Circadian orchestration of the hepatic proteome. Current Biology 16 1107-1115.

Reddy AB, Maywood ES, Karp NA, King VM, Inoue Y, Gonzalez FJ, Lilley KS, Kyriacou CP \& Hastings MH 2007 Glucocorticoid signaling synchronizes the liver circadian transcriptome. Hepatology 45 1478-1488.

Reick M, Garcia JA, Dudley C \& McKnight SL 2001 NPAS2: an analog of clock operative in the mammalian forebrain. Science 293 506-509.

Reinke H, Saini C, Fleury-Olela F, Dibner C, Benjamin IJ \& Schibler U 2008 Differential display of DNA-binding proteins reveals heat-shock factor 1 as a circadian transcription factor. Genes and Development 22 331-345.

Remacle C, Dumortier O, Bol V, Goosse K, Romanus P, Theys N, Bouckenooghe T \& Reusens B 2007 Intrauterine programming of the endocrine pancreas. Diabetes, Obesity and Metabolism 9 (Suppl 2) 196-209.

Renn SC, Park JH, Rosbash M, Hall JC \& Taghert PH 1999 A pdf neuropeptide gene mutation and ablation of PDF neurons each cause severe abnormalities of behavioral circadian rhythms in Drosophila. Cell 99 791-802.

Reppert SM, Artman HG, Swaminathan S \& Fisher DA 1981 Vasopressin exhibits a rhythmic daily pattern in cerebrospinal fluid but not in blood. Science 213 1256-1257.

Reyes TM, Walker JR, DeCino C, Hogenesch JB \& Sawchenko PE 2003 Categorically distinct acute stressors elicit dissimilar transcriptional profiles in the paraventricular nucleus of the hypothalamus. Journal of Neuroscience 23 5607-5616.

Roenneberg T \& Merrow M 2002 'What watch?...such much!' complexity and evolution of circadian clocks Cell and Tissue Research 309 3-9.

Rosato E, Tauber E \& Kyriacou CP 2006 Molecular genetics of the fruit-fly circadian clock. European Journal of Human Genetics 14 729-738.

Saeb-Parsy K, Lombardelli S, Khan FZ, McDowall K, Au-Yong IT \& Dyball RE 2000 Neural connections of hypothalamic neuroendocrine nuclei in the rat. Journal of Neuroendocrinology 12 635-648.

Sage D, Maurel D \& Bosler O 2001 Involvement of the suprachiasmatic nucleus in diurnal ACTH and corticosterone responsiveness to stress. American Journal of Physiology. Endocrinology and Metabolism 280 E260-E269.

Sage D, Maurel D \& Bosler O 2002 Corticosterone-dependent driving influence of the suprachiasmatic nucleus on adrenal sensitivity to ACTH. American Journal of Physiology. Endocrinology and Metabolism 282 E458-E465.
Sage D, Ganem J, Guillaumond F, Laforge-Anglade G, Francois-Bellan AM, Bosler O \& Becquet D 2004 Influence of the corticosterone rhythm on photic entrainment of locomotor activity in rats. Journal of Biological Rhythms 19 144-156.

Saper CB, Lu J, Chou TC \& Gooley J 2005 The hypothalamic integrator for circadian rhythms. Trends in Neurosciences 28 152-157.

Sarnyai Z, Veldhuis JD, Mello NK, Mendelson JH, Eros-Sarnyai M, Mercer G, Gelles H \& Kelly M 1995 The concordance of pulsatile ultradian release of adrenocorticotropin and cortisol in male rhesus monkeys. Journal of Clinical Endocrinology and Metabolism 80 54-59.

Sato TK, Yamada RG, Ukai H, Baggs JE, Miraglia LJ, Kobayashi TJ, Welsh DK, Kay SA, Ueda HR \& Hogenesch JB 2006 Feedback repression is required for mammalian circadian clock function. Nature Genetics $\mathbf{3 8}$ 312-319.

Sawchenko PE, Swanson LW \& Vale WW 1984a Co-expression of corticotropin-releasing factor and vasopressin immunoreactivity in parvocellular neurosecretory neurons of the adrenalectomized rat. PNAS $\mathbf{8 1}$ 1883-1887.

Sawchenko PE, Swanson LW \& Vale WW $1984 b$ Corticotropin-releasing factor: co-expression within distinct subsets of oxytocin-, vasopressin-, and neurotensin-immunoreactive neurons in the hypothalamus of the male rat. Journal of Neuroscience 4 1118-1129.

Schibler U \& Sassone-Corsi P 2002 A web of circadian pacemakers. Cell 111 919-922.

Seckl JR 2008 Glucocorticoids, developmental 'programming' and the risk of affective dysfunction. Progress in Brain Research 167 17-34.

Segall LA, Perrin JS, Walker CD, Stewart J \& Amir S 2006 Glucocorticoid rhythms control the rhythm of expression of the clock protein, Period2, in oval nucleus of the bed nucleus of the stria terminalis and central nucleus of the amygdala in rats. Neuroscience 140 753-757.

Siepka SM, Yoo SH, Park J, Song W, Kumar V, Hu Y, Lee C \& Takahashi JS 2007 Circadian mutant overtime reveals F-box protein FBXL3 regulation of cryptochrome and period gene expression. Cell 129 1011-1023.

Srivastava AK \& Meier AH 1972 Daily variation in concentration of cortisol in plasma in intact and hypophysectomized gulf killifish. Science $\mathbf{1 7 7}$ 185-187.

Stahn C, Lowenberg M, Hommes DW \& Buttgereit F 2007 Molecular mechanisms of glucocorticoid action and selective glucocorticoid receptor agonists. Molecular and Cellular Endocrinology 275 71-78.

Stephan FK 2002 The 'other' circadian system: food as a Zeitgeber. Journal of Biological Rhythms 17 284-292.

Stephan FK, Berkley KJ \& Moss RL 1981 Efferent connections of the rat suprachiasmatic nucleus. Neuroscience 6 2625-2641.

Stocco DM, Wang X, Jo Y \& Manna PR 2005 Multiple signaling pathways regulating steroidogenesis and steroidogenic acute regulatory protein expression: more complicated than we thought. Molecular Endocrinology 19 2647-2659.

Stokkan KA, Yamazaki S, Tei H, Sakaki Y \& Menaker M 2001 Entrainment of the circadian clock in the liver by feeding. Science 291 490-493.

Storch KF, Lipan O, Leykin I, Viswanathan N, Davis FC, Wong WH \& Weitz CJ 2002 Extensive and divergent circadian gene expression in liver and heart. Nature 417 78-83.

Storch KF, Paz C, Signorovitch J, Raviola E, Pawlyk B, Li T \& Weitz CJ 2007 Intrinsic circadian clock of the mammalian retina: importance for retinal processing of visual information. Cell 130 730-741.

Swanson LW, Sawchenko PE, Rivier J \& Vale WW 1983 Organization of ovine corticotropin-releasing factor immunoreactive cells and fibers in the rat brain: an immunohistochemical study. Neuroendocrinology 36 165-186.

Szafarczyk A, Ixart G, Malaval F, Nouguier-Soule J \& Assenmacher I 1979 Effects of lesions of the suprachiasmatic nuclei and of $p$-chlorophenylalanine on the circadian rhythms of adrenocorticotrophic hormone and corticosterone in the plasma, and on locomotor activity of rats. Journal of Endocrinology 83 1-16.

Tapp WN, Holaday JW \& Natelson BH 1984 Ultradian glucocorticoid rhythms in monkeys and rats continue during stress. American Journal of Physiology 247 R866-R871. 
Terazono H, Mutoh T, Yamaguchi S, Kobayashi M, Akiyama M, Udo R, Ohdo S, Okamura H \& Shibata S 2003 Adrenergic regulation of clock gene expression in mouse liver. PNAS 100 6795-6800.

Tharp GD \& Folk GE Jr 1965 Rhythmic changes in rate of the mammalian heart and heart cells during prolonged isolation. Comparative Biochemistry and Physiology 14 255-273.

Torra IP, Tsibulsky V, Delaunay F, Saladin R, Laudet V, Fruchart JC, Kosykh V \& Staels B 2000 Circadian and glucocorticoid regulation of Rev-erbalpha expression in liver. Endocrinology 141 3799-3806.

Torres-Farfan C, Seron-Ferre M, Dinet V \& Korf HW 2006 Immunocytochemical demonstration of day/night changes of clock gene protein levels in the murine adrenal gland: differences between melatonin-proficient $(\mathrm{C} 3 \mathrm{H})$ and melatonin-deficient (C57BL) mice. Journal of Pineal Research 40 64-70.

Ueda HR, Hayashi S, Chen W, Sano M, Machida M, Shigeyoshi Y, Iino M \& Hashimoto S 2005 System-level identification of transcriptional circuits underlying mammalian circadian clocks. Nature Genetics 37 187-192.

Ueyama T, Krout KE, Nguyen XV, Karpitskiy V, Kollert A, Mettenleiter TC \& Loewy AD 1999 Suprachiasmatic nucleus: a central autonomic clock. Nature Neuroscience 2 1051-1053.

Ulrich-Lai YM \& Engeland WC 2000 Rat adrenal transplants are reinnervated: an invalid model of denervated adrenal cortical tissue. Journal of Neuroendocrinology 12 881-893.

Ulrich-Lai YM, Arnhold MM \& Engeland WC 2006 Adrenal splanchnic innervation contributes to the diurnal rhythm of plasma corticosterone in rats by modulating adrenal sensitivity to ACTH. American Journal of Physiology. Regulatory, Integrative and Comparative Physiology 290 R1128-R1135.

Vallone D, Lahiri K, Dickmeis T \& Foulkes NS 2007 Start the clock! Circadian rhythms and development. Developmental Dynamics 236 142-155.

Veldhuis JD, Iranmanesh A, Johnson ML \& Lizarralde G 1990 Amplitude, but not frequency, modulation of adrenocorticotropin secretory bursts gives rise to the nyctohemeral rhythm of the corticotropic axis in man. Journal of Clinical Endocrinology and Metabolism 71 452-463.

Vrang N, Larsen PJ \& Mikkelsen JD 1995 Direct projection from the suprachiasmatic nucleus to hypophysiotrophic corticotropin-releasing factor immunoreactive cells in the paraventricular nucleus of the hypothalamus demonstrated by means of Phaseolus vulgaris - leucoagglutinin tract tracing. Brain Research 684 61-69.

Vujovic N, Davidson AJ \& Menaker M 2008 Sympathetic input modulates, but does not determine, phase of peripheral circadian oscillators. American Journal of Physiology. Regulatory, Integrative and Comparative Physiology 295 R355-R360.

Watts AG, Swanson LW \& Sanchez-Watts G 1987 Efferent projections of the suprachiasmatic nucleus: I. Studies using anterograde transport of Phaseolus vulgaris leucoagglutinin in the rat. Journal of Comparative Neurology 258 204-229.

Watts AG, Tanimura S \& Sanchez-Watts G 2004 Corticotropin-releasing hormone and arginine vasopressin gene transcription in the hypothalamic paraventricular nucleus of unstressed rats: daily rhythms and their interactions with corticosterone. Endocrinology 145 529-540.

Weitzman ED, Fukushima D, Nogeire C, Roffwarg H, Gallagher TF \& Hellman L 1971 Twenty-four hour pattern of the episodic secretion of cortisol in normal subjects. Journal of Clinical Endocrinology and Metabolism 33 14-22.

Welsh DK, Logothetis DE, Meister M \& Reppert SM 1995 Individual neurons dissociated from rat suprachiasmatic nucleus express independently phased circadian firing rhythms. Neuron 14 697-706.
Welsh DK, Yoo SH, Liu AC, Takahashi JS \& Kay SA 2004 Bioluminescence imaging of individual fibroblasts reveals persistent, independently phased circadian rhythms of clock gene expression. Current Biology 14 2289-2295.

Whitmore D, Foulkes NS, Strahle U \& Sassone-Corsi P 1998 Zebrafish Clock rhythmic expression reveals independent peripheral circadian oscillators. Nature Neuroscience 1 701-707.

Whitmore D, Foulkes NS \& Sassone-Corsi P 2000 Light acts directly on organs and cells in culture to set the vertebrate circadian clock. Nature $\mathbf{4 0 4}$ 87-91.

Whitnall MH, Mezey E \& Gainer H 1985 Co-localization of corticotropinreleasing factor and vasopressin in median eminence neurosecretory vesicles. Nature 317 248-250.

Windle RJ, Wood SA, Lightman SL \& Ingram CD 1998a The pulsatile characteristics of hypothalamo-pituitary-adrenal activity in female Lewis and Fischer 344 rats and its relationship to differential stress responses. Endocrinology 139 4044-4052.

Windle RJ, Wood SA, Shanks N, Lightman SL \& Ingram CD $1998 b$ Ultradian rhythm of basal corticosterone release in the female rat: dynamic interaction with the response to acute stress. Endocrinology 139 443-450.

Windle RJ, Wood SA, Kershaw YM, Lightman SL, Ingram CD \& Harbuz MS 2001 Increased corticosterone pulse frequency during adjuvant-induced arthritis and its relationship to alterations in stress responsiveness. Journal of Neuroendocrinology 13 905-911.

Wuarin J, Falvey E, Lavery D, Talbot D, Schmidt E, Ossipow V, Fonjallaz P \& Schibler U 1992 The role of the transcriptional activator protein DBP in circadian liver gene expression. Journal of Cell Science 16 123-127.

Yamamoto T, Nakahata Y, Tanaka M, Yoshida M, Soma H, Shinohara K, Yasuda A, Mamine T \& Takumi T 2005 Acute physical stress elevates mouse period1 mRNA expression in mouse peripheral tissues via a glucocorticoid-responsive element. Journal of Biological Chemistry 280 42036-42043.

Yamazaki S, Kerbeshian MC, Hocker CG, Block GD \& Menaker M 1998 Rhythmic properties of the hamster suprachiasmatic nucleus in vivo. Journal of Neuroscience 18 10709-10723.

Yamazaki S, Numano R, Abe M, Hida A, Takahashi R-I, Ueda M, Block GD, Sakaki Y, Menaker M \& Tei H 2000 Resetting central and peripheral circadian oscillators in transgenic rats. Science 288 682-685.

Yang X, Downes M, Yu RT, Bookout AL, He W, Straume M, Mangelsdorf DJ \& Evans RM 2006 Nuclear receptor expression links the circadian clock to metabolism. Cell 126 801-810.

Yoo SH, Yamazaki S, Lowrey PL, Shimomura K, Ko CH, Buhr ED, Siepka SM, Hong H-K, Oh WJ, Yoo OJ et al. 2004 PERIOD2::LUCIFERASE real-time reporting of circadian dynamics reveals persistent circadian oscillations in mouse peripheral tissues. PNAS 101 5339-5346.

Yoon JC, Puigserver P, Chen G, Donovan J, Wu Z, Rhee J, Adelmant G, Stafford J, Kahn CR, Granner DK et al. 2001 Control of hepatic gluconeogenesis through the transcriptional coactivator PGC-1. Nature 413 $131-138$.

Zheng X \& Sehgal A 2008 Probing the relative importance of molecular oscillations in the circadian clock. Genetics 178 1147-1155.

\section{Received in final form 22 October 2008 \\ Accepted 25 October 2008 \\ Made available online as an Accepted Preprint 29 October 2008}

